\title{
Identification of metrics used by decision makers to determine the efficacy of wireless communication systems in higher education
}

\author{
Karen R. Petitto \\ West Virginia University
}

Follow this and additional works at: https://researchrepository.wvu.edu/etd

\section{Recommended Citation}

Petitto, Karen R., "Identification of metrics used by decision makers to determine the efficacy of wireless communication systems in higher education" (2003). Graduate Theses, Dissertations, and Problem Reports. 2514.

https://researchrepository.wvu.edu/etd/2514

This Dissertation is protected by copyright and/or related rights. It has been brought to you by the The Research Repository @ WVU with permission from the rights-holder(s). You are free to use this Dissertation in any way that is permitted by the copyright and related rights legislation that applies to your use. For other uses you must obtain permission from the rights-holder(s) directly, unless additional rights are indicated by a Creative Commons license in the record and/ or on the work itself. This Dissertation has been accepted for inclusion in WVU Graduate Theses, Dissertations, and Problem Reports collection by an authorized administrator of The Research Repository @ WVU.

For more information, please contact researchrepository@mail.wvu.edu. 
Identification of Metrics Used by Decision Makers to Determine the Efficacy of Wireless Communication Systems in Higher Education

Karen R. Petitto, BA, MEd

\author{
Dissertation submitted to the \\ College of Human Resources and Education \\ at West Virginia University \\ in partial fulfillment of the requirements \\ for the degree of
Doctor of Education
in \\ Technology Education
}
George R. Maughan, Ed.D., Chair
Ernest R. Goeres, Ph.D.
David L. McCrory, Ph.D.
Beth Thorne Newcome, Ph.D.
Floyd L. Stead, Ed.D.

Department of Technology Education

Morgantown, West Virginia

2003

Keywords: Wireless Networks, Higher Education, Campus Networks, Wireless Efficacy, Wireless Metrics

Copyright 2003 Karen R. Petitto 


\begin{abstract}
Identification of Metrics Used by Decision Makers to Determine the Efficacy of Wireless Communication Systems in Higher Education

Karen R. Petitto

This research described the wireless network technologies that are available for use in higher education, determined the categories of metrics used to evaluate wireless network efficacy, and yielded a self-assessment instrument for guiding small college administrators considering wireless local area network systems.

The features and benefits of contemporary wireless systems in higher education were identified through a review of the professional journals, government publications, and standards industry documentation. The literature identified three categories of metrics beneficial for the evaluation of efficacy of wireless campus local area networks: cost, speed, and reliability. After identification of these categories of metrics, a modified Delphi technique was administered to ten wireless network experts in higher education. The expert group was made up of seven higher education wireless decision makers and three wireless industry professionals.

The wireless experts responded to Instrument One which identified 27 metrics in the three categories of metrics. The experts generated 19 essential metrics: four in the category of cost, seven in the category of speed, and eight in the category of reliability. Eight supplemental metrics were also identified in Instrument One: four in the category of cost, two in the category of speed, and two in the category of reliability.

Instrument Two generated 27 questions to guide wireless decision makers in higher education. These metrics offer a timeless guide to wireless system planning on small college campuses. The self-assessment instrument will assist in gathering information specific to the small college environment, and in gathering current specifications for wireless network systems. The analysis of information gained from the use of this tool will help wireless campus networks to operate as an integrated part of teaching and learning.
\end{abstract}




\section{ACKNOWLEDGEMENTS}

I would like to express my appreciation to each of my committee

members: Dr. George R. Maughan, Dr. Ernest R. Goeres, Dr. David L. McCrory, Dr. Beth Thorne Newcome, and Dr. Floyd L. Stead. Each of you has been with me since I began my program in the fall of 1996. You have each supported and encouraged my academic success and have been available to guide my research. Thank you Carol and Ann for being faithful liaisons between busy professors and a commuting student; without your assistance, the logistics would have been an insurmountable obstacle for me.

To my friends and colleagues at West Virginia Wesleyan College, your confidence that I would complete my degree kept me going during all the research and writing that challenged me sometimes beyond my limits. Also, to the College I want to thank you for the library resources, time, and financial support that enabled me to complete my degree.

Thank you Aaron, Sarah, Annie, and Maggie who have asked repeatedly “Are you done yet, Mom?” The answer is finally, "Yes!” To my parents and all my family, you have given selflessly of your time to care for my children so that I could study; I couldn't have done it without you. And most importantly to Michael, who never let me consider quitting and who sacrificed more than any spouse should ever be asked, your loving encouragement and patience have been immeasurable. 


\section{TABLE OF CONTENTS}

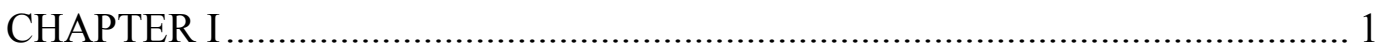

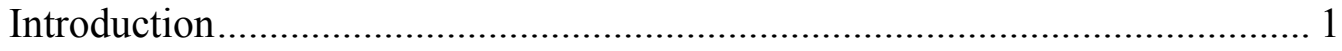

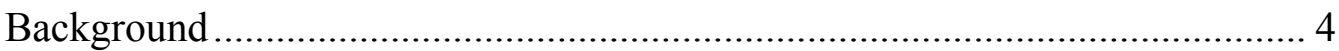

Integration of Network Computer Technology on Campus......................... 4

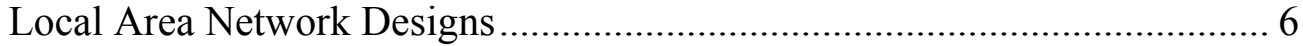

Problem Statement ............................................................................. 16

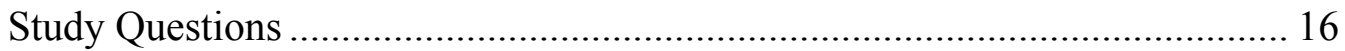

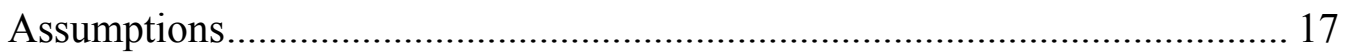

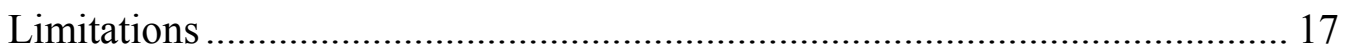

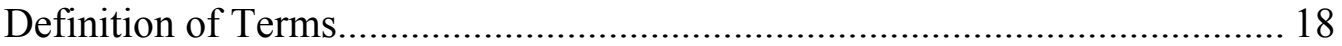

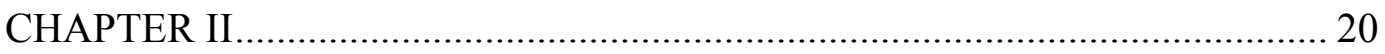

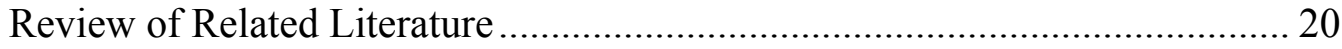

Use of Networks for Instruction ....................................................... 20

Campus Local Area Networks ............................................................. 24

Components of Wireless Campus Networks ........................................... 30

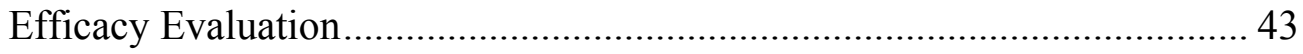

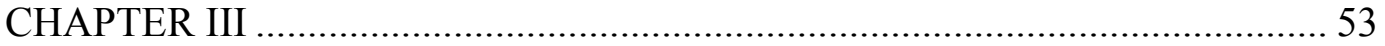

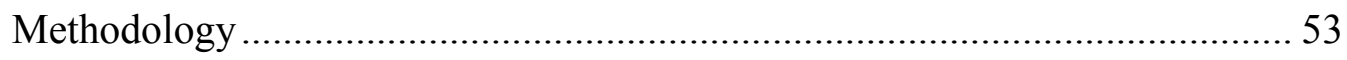

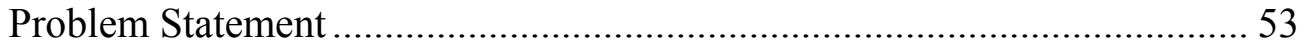




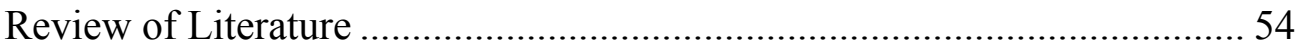

Creation of the Modified Delphi Instrument ............................................. 54

Identification of Expert Panelists ....................................................... 58

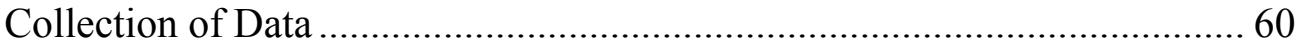

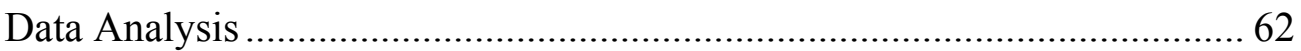

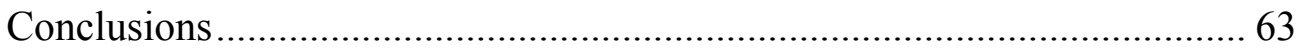

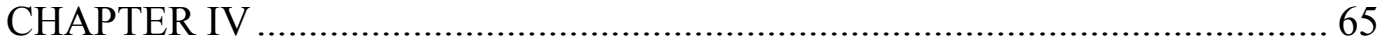

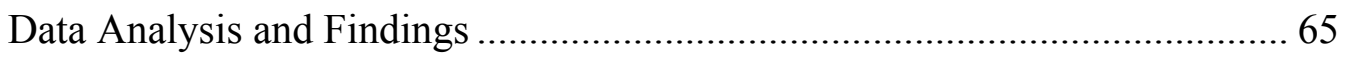

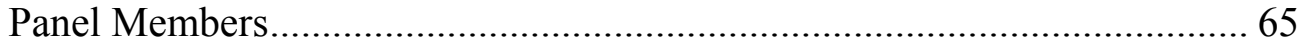

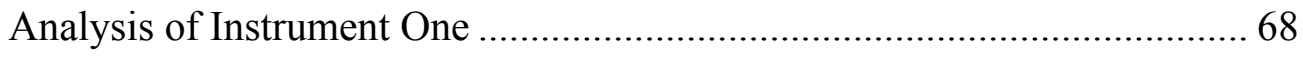

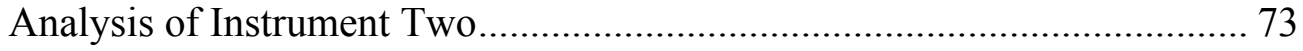

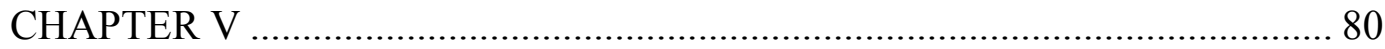

Summary, Conclusions, Discussion, Implications, and Recommendations ..... 80

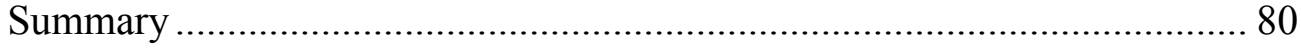

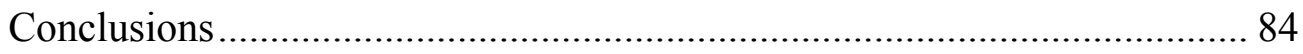

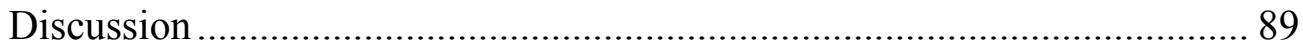

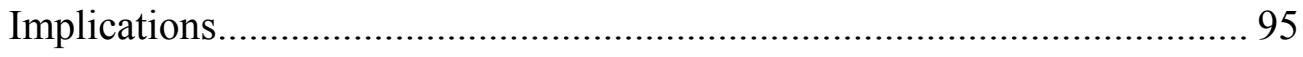

Recommendations for Further Research............................................. 99

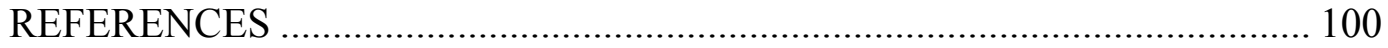

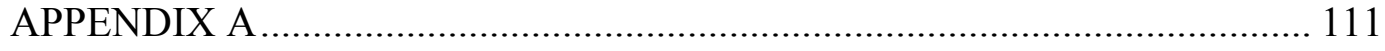

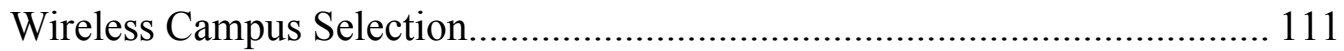




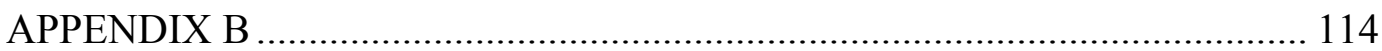

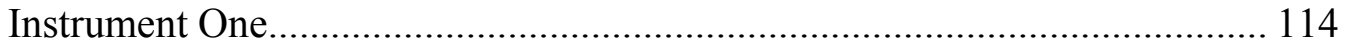

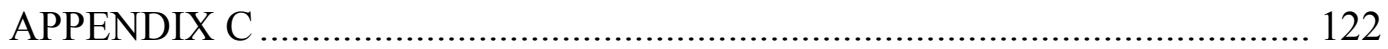

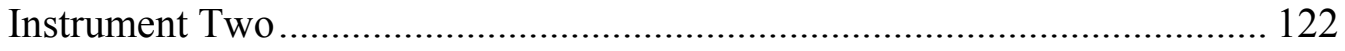

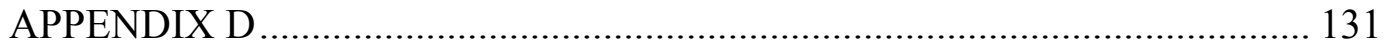

Self-Assessment Instrument.............................................................. 131

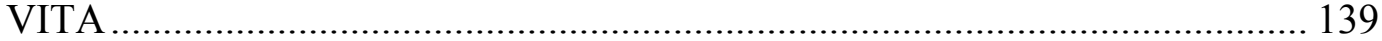




\section{CHAPTER I}

Introduction

American colleges have been investing millions of dollars in wiring their campuses for the past decade. As quickly as many college campuses have met the wired network environment, wireless networks are outdating them. Proponents of wireless networks say this technology offers more flexibility for students and professors (Brown, 1998; Young, 1999). Wireless technologies continue to be identified as one of the most important emerging technologies on college campuses by the Educause Evolving Technologies Committee (Cohen, 2000).

The acquisition of information technologies has been emerging as a leading trend in colleges and universities since 1988, and there is significant research to support that these technologies will continue to propagate our campuses (Green, 2001; Brown, 1999). Information technology has and will continue to change the way institutions of higher education go about the business of educating America's college students. Specifically, in the liberal arts setting, strategic planning and the maturity of information technology systems can resculpt the standards for higher education (Brown, Burg, and Dominick, 1998). Wireless networks can enable a broad spectrum of new uses of technology in higher education including more effective collaboration techniques, computermediated communication models, mobility, and information access that will enhance the role of the faculty member and the student. Institutions of higher 
education are investing millions of dollars every year in computer technology, and they are committing to a long-term level of support for these programs (Holleque and Cartwright, 1997).

Wireless network alternatives are attractive to college administrators, faculty, and students alike. Wireless local area networks (LANs) promote the most flexible of all connected environments, allowing users to access the Internet and all its resources from a non-tethered computer and from thousands of locations on campus.

There are a number of reasons why colleges might consider wireless networks. The computers they support may be mobile; the construction of the building may not easily accommodate new wiring; or the users might often need to quickly and easily reconfigure the rooms or entire buildings (McKenzie, 1999). Traditional institutions who are establishing new technology plans must accommodate buildings that were constructed throughout their history, sometimes as long as 200 years ago. Wireless technologies are one component of the technology infrastructure that can turn even the oldest building into state-of-theart connected classrooms and technology rich environments without a need for major remodeling. Wireless networks offer network bridges within buildings and between buildings that would otherwise require underground trenches, access to right-of-way or above ground line leasing (Harler, 1999). Beyond the architectural functionality of wireless networks, colleges must recognize the 
flexibility and user-centered design that wireless networks offer to digital college environments (Jones, Reiger, Treadwell, and Gay, 2000). Colleges are quickly moving forward with implementation strategies that include wireless solutions; it will be necessary to carefully evaluate the outcomes.

Evaluation strategies will help facilitate the measurement of the advantages and disadvantages of wireless technologies. The main issues in the efficacy of wireless networks are cost, speed, reliability, and the effect on the teaching and learning process (Jones et al, 2000, Young, 1999). The topic of this research was to identify the metrics that will aid decision makers in institutions of higher education in evaluating the efficacy of wireless local area networks on college campuses. The research yielded a self-assessment instrument for guiding decision making for small colleges considering wireless systems. 


\section{Background}

\section{Integration of Network Computer Technology on Campus}

Computer technology in the classroom has been prevalent in many ways since the 1970s. The first demonstration of computers in the classroom appeared with teachers isolating a specific skill and applying a specific computer aided solution to address it. Freestanding computers that were used for the purpose of introducing or reinforcing particular concepts were an effective strategy. Different disciplines have since introduced more effective computer strategies into the curriculum, creating environments where teachers and learners can excel based on their individual strengths (Lysiak, Wallace, and Evans, 1976; Laurillard, 1978; Atkins, 1993).

As new information technologies emerge, electronic activities that support coursework are becoming commonplace on college campuses. Searching library databases, electronic communication, and online reading assignments are all examples of electronic course activities. A reliable network environment is critical to sustaining these new learning technologies (Manning, 1997). Networks further enrich the learning environment by providing new channels of communication. The networked computer provides unlimited resources from around the world to be more readily integrated in the classroom. Electronic mail facilitates communication among students and faculty, administrators, and the 
outside world. Electronic student participation in coursework and discussion adds a dimension to the faculty/student relationship, as well as adding a new medium for communication (Arduini, 2000; Morton, 1997). Networks provide the channel for students to share documents and resources, to access information from anywhere, and to connect with information resources and people from around the world (Luker, 2000). Networks are limitless in their application to the higher education classroom; content areas of a broad range can effectively apply network learning strategies into their pedagogy (Lee, 1999).

The combination of networks and mobile computing can have a dramatic effect on the use of information technologies in higher education. Wireless networks can facilitate the use of computers so that students can participate in interactive computer events in a classroom environment (Iroff and Sawhill, 2000). The wireless network can be used as an interface among students, between faculty and students and between the college campus and the global community (Fishman, 1996). Digitally enabled web-based research allows the user access to full text publications electronically. These primary resources can be more readily integrated into coursework and can allow students to participate more fully in the process (Jones, 2000). The efficacy of wireless networks can enhance or diminish the network activities on a college campus. The purpose of this research was to identify the metrics necessary to evaluate the efficacy of wireless networks and 
create an evaluation instrument that could guide decision making for small colleges considering wireless systems.

\section{Local Area Network Designs}

Overview of Wired Networks

LANs connect remote and mobile computers and workstations to the wired network. They permit wireless communication between desktops and other devices and connect systems in classrooms, offices, or even different buildings. Local area networks and computing technology are continually in transition on college campuses; in this dynamic environment, wireless networks are becoming more popular but are still in their infancy (Barone and Luker, 2000, Manning, 1997).

LAN technologies have a set parameter of hardware and software that support their operation on small college campuses. Wiring closets are the hardware that distributes networking via switches or hubs within a building. Wiring closets can be interconnected with twisted-pair cable or fiber-optic cable. Fiber-optic cable is a better choice for a variety of reasons, most importantly for achieving higher signal transmission rates (Barry, 1998). From the wiring closet the wiring plan then accommodates a plug-in point, or port, for every computer. Short and long term technology goals need to be considered when planning the number of network connections per room. The use of each room determines the 
number of network jacks that should be installed (Minoli and Alles, 1996). Dormitories typically house one port per occupant; offices typically follow this same standard. Classrooms should be wired in cooperation with the registrar or other internal office that has responsibility for scheduling classes, faculty members and technicians working as a team to plan the most effective network distribution (Kovac and Jones, 1999).

The library is a versatile center for research and access to information; therefore, special attention is given to the network infrastructure in the library facility (Jones et al, 2000). Many libraries often manage servers to deliver dedicated information services. Digital information combined with campus networks opens the library to faculty and students 24 hours a day. Networked computers can be used to access an online card catalog within the local school or online catalogs from other institutions. Internet databases provide a plethora of primary resources which were not available to the student researcher as few as four years ago. A local area network allows every computer in the library on the campus to access online catalogs and databases from a variety of locations. Many libraries locate network connections in as many places as possible creating an environment where their patrons have access to information from online databases from the local library, libraries around the world, government agencies and other research organizations (Ruzic, 2000). 
Overview of Wireless Campus Systems

There are two distinct ways that wireless communication systems can be used in higher education. Transmitting data to another school location or to a third party can allow data transmission facilitated by satellite technology using wireless in a wide area network environment (Harler, 1999). These microwavebased technologies are the most familiar, as they are the most widely used technology in the personal communication systems industry (Siau and Shen, 2003). There are 3 distinct types of long-range wireless transmission systems: Multi-Channel Multipoint Distribution Service (MMDS), Local Multipoint Distribution Service (LMDS), and satellites. MMDS is a mechanism for video distribution that utilizes microwave frequencies to transmit video programming through line-of-sight rooftop antennas. MMDS requires the location of antennas within the line-of-sight of transmitters. The typical MMDS transmitter covers between 30 and 40 miles. Multi-Channel Multipoint Distribution Service is typically the wireless service of choice for one-way communication. LMDS transmits several different media: data, voice, and video signals within cells that are typically three to ten miles in diameter. LMDS allows for two-way data transmission with the data passing through the central hub. Satellites are the third category in an ever-increasing number of communications technology applications (Varshney, 1999). 
Originally, satellites were used as connections between major land-based facilities (Stallings, 1997; Tang and Baker, 1999). The continuing decrease in equipment costs combined with satellites' increased transmitting strength, now makes it practical for end-users to receive and send information directly to a satellite. Though costs are decreasing, deploying satellite systems still requires a large investment and a large commitment to the sustained use of the equipment. Small college campuses are less likely to invest in this type of wireless system. Localized systems are more appropriate when considering that the teaching and learning that occurs on college campuses is the main focus of business for higher education (Cohen, 2000; Jones et al, 2000).

A wireless local area network, a network without wires, is similar to a wired network except that radio technologies or infrared techniques are used to transmit and receive data. On small college campuses wireless systems are wireless LANs that provide transmission channels within a campus environment. Freestanding wireless networks and wireless networks that are layered with existing wired communication technologies are being explored by many colleges (Harler, 1999). A local area network (LAN) is a group of computers and associated devices that share a common communication line and typically share the resources of a single processor or server within a small geographic area (for example, within a classroom building or library). The server has applications and data storage that are shared in common by multiple computer users. By utilizing 
radio frequencies, or infrared, wireless local area networks provide connectivity within and between buildings without the need for physical wires (McGinity, 1999).

The working range of the wireless LAN varies from $100-900$ feet in a typical office installation. In an open classroom, as opposed to wall and door, brick and mortar construction, wireless systems can gain greater operating ranges. The installation of access points with overlapping signal areas can extend the wireless area and can add stability to the wireless user. The user expects to move around freely in a wireless environment without losing and regaining the network signal. Additional access points can overlap signals and allow the signal to migrate from one point to another for seamless connections to the user. With multiple access points, computer users may roam from one access point's signal range to another with uninterrupted connectivity and no signal degradation. Building to building networks can be made through the use of directional antennas and the coexistence of microwave technologies. The data are converted into a signal suitable for sending by the transmitter and is then sent through the channel.

There are several design possibilities in a wireless LAN environment. A base to remote configuration provides workstations and personal computers with links to a central base workstation. Because the base workstation is the hub of the local area network, excellent signal propagation, range, and high security levels 
are required. As part of the nature of distributed networks, more demanding network management functions are required. Base to remote systems work well either as a standalone wireless local area network or as an extension to a wired environment specifically in single buildings or buildings in close proximity.

Peer-to-peer wireless LANs permit direct communication between the wireless devices without going through a base station or central access point. Peer-to-peer networks allow rapid installation and are well suited to extemporaneous meetings and gatherings. The disadvantages of peer-to-peer networks are that security and network management concerns are not easily addressed as they are in microcellular wireless systems, as security features are built into microcellular operating systems. The range of communications is also limited in peer-to-peer networks.

Infrared technologies are limited in their range and their precise point-topoint topology. This limitation makes frequency technology most proliferate among the available alternatives for campuses (Lindgren, 1999). Radio frequency has filled the gap for campuses who cannot afford the $\$ 100,000$ satellite alternatives and have a need for application and user support that is more sophisticated than just point-to-point printing or file sharing. The emerging trends in higher education are demanding that networks support more than computers with wireless communications services. Personal computers, pagers, cordless 
phones, cellular phones, and all kinds of personal communication services are going to continue to be a part of small college campus landscapes.

Microcellular wireless LANs use access points on a wired backbone that permit the client devices to communicate to any backbone-connected device or to any other wireless device connected to the backbone through the same or another access point. Microcellular configurations also permit seamless roaming from cell to cell when the coverage of those cells via access points provides sufficient overlap. The most widely available wireless local area network configuration among institutions of higher education is the microcellular network, and it is, therefore, the focus of this research.

The institution of the IEEE 802.11b standard in the microcellular wireless industry in 1998 has changed the way many network designers are thinking about the use of this technology (Langley, 1999). This standard is the agreed upon technical protocol for the manufacturing of the wireless antennas and the computer device. The IEEE, the Institute of Electrical and Electronics Engineers, a membership organization that sets the standards for the communications industry, developed these standards. This standard has enabled colleges to offer access to buildings where access would not have been possible in the past. Pulling wires to every place on campus where students may gather is not possible (Harler, 1999). Adding a layer of wireless access to an existing wired backbone can make access on a college campus virtually seamless. 


\section{Evaluating Efficacy}

Cost. Information technology costs in higher education have been on the rise since the first computers were seen in the teaching and learning process. The networking costs associated with the communication and information technology infrastructure is one of the most important variables. In order for a college campus to embark on an information technology initiative, they must have a budget model that will support their strategy. Over an eleven-year period, Kenneth Green has found that cost considerations are among the highest concerns of administrators in relation to computing on campus (Green, 2000). The adoption of the IEEE $802.11 \mathrm{~b}$ standard for communication of wireless devices has brought the wireless LANs into a price range that now makes wireless LAN a viable alternative for many institutions. This standard allows intercommunication among devices made by different manufacturers offering leverage to colleges, which converts directly to purchasing power (Bennington and Bartel, 2001). In a study conducted by Johns Hopkins University School of Public Health, wireless infrastructure alternatives for classrooms were found to be considerably less expensive than wired (McKenzie, 1999).

Speed. The second measure of network efficacy is the speed of the network. There are several fixed variables in measuring the speed of a network. The most evident measure of speed is the specification of the access points and PC cards. The IEEE 802.11b standard for Direct Sequence Spread Spectrum at 
the $2.4 \mathrm{GHz}$ frequency is 11 Megabits per second (MB). This standard addresses the potential of the equipment. The next variable in the measure of speed is the traffic, the minimum and maximum number of users that are connected to each access point. Attention needs to be given to the placement of access points in order to provide adequate coverage for the typical campus network user. The radio frequency wireless LAN technology that was selected assumes the existence of a wired campus infrastructure. This wired foundation of the network introduces other variables into the equation. There are several alternatives for materials in the physical wiring of a wired environment: copper, fiber optic, ATM, or the newest standard, Gigabit Ethernet. The workload, specification, and speed of the servers that connect the campus network are also variables in overall network speed (Minoli and Alles, 1996).

Reliability. Network reliability is the third measure of efficacy that this study addressed. Network reliability addresses the ability of the communication system to give the same results in successive trials. Does the wireless communication system offer sufficient aggregate bandwidth to handle unscheduled, unplanned movements of fixed or mobile computers that college campuses support? Furthermore, the system will be much more efficient if it supports optimal routing to each computer without requiring modification of networking software on each hardware component in the network (Harler, 1999). 
The case remains strong that college campuses should investigate the needs of the population as the first step in design and topology of the network; concurrently, there needs to be an infrastructure in place for the development, support, and ongoing evaluation and response of a communication system in any institution of higher education. This infrastructure should consist of institutional planning, access, staffing, support, and resources. When selecting appropriate technology systems, the major guidelines are, thus, the quality of software and hardware, the support services that are available, the availability of resources, ubiquitous access, and institutional use (Barone and Luker, 2000; Brown, 1999). Combined with analysis of the network needs and total evaluation of the network, administrators can begin to make more quantitative decisions about technology deployment on campuses.

Teaching and Learning. The opportunities for more diverse classroom strategies and information access can have a very positive effect on college campuses (Brooks and Brooks, 1999). There are many ways the wireless networks can have a positive impact on college campuses. The main focus of higher education is instruction. In every facet of a college campus, one will see technology. A few examples of how network computers are being used in teaching and learning include course management systems, grading, project collaboration, student and faculty access to email, online assignments, electronic research resources, and access to the Internet. The use of networks on college 
campuses must include planning and recommendations for its productivity in instructional strategies and goals (Oblinger and Rush, 1997).

\section{Problem Statement}

The problem of this research is that metrics to assess wireless networks for small college system administrators to use for decision making do not currently exist. This research examined wireless technologies that are available for use in higher education, determined the categories of metrics used to evaluate wireless local area network efficacy, and created an assessment instrument for guiding small college administrators considering wireless local area network systems.

\section{Study Questions}

The questions of this study are:

1. What are the features and benefits of contemporary wireless systems in Higher Education?

2. What are the categories of metrics used to determine the efficacy of the application of wireless campus networks?

3. What questions should decision makers ask to provide critical selfassessment measures of wireless system efficacy? 


\section{Assumptions}

The assumptions for this study are:

1. Computer networks are an integral part of the teaching/learning construct.

2. Wireless technologies are an important emerging technology on college campuses.

\section{Limitations}

The limitations of this study are:

1. The research is limited to single-campus colleges in the United States with a student population under 3,000 undergraduates.

2. This research is limited to the use of wireless network systems for academic coursework, communication and research. The use of wireless networks for performance of higher education administration systems will require further investigation.

3. The radio frequency wireless LAN technology that this research addresses assumes the existence of a wired campus infrastructure.

4. This research does not address measures of data security. The research assumes that wireless LANs include inherent security measures specified in the 80211.b Wireless Equivalent Privacy (WEP) protocol, providing security while allowing devices to easily access and interact with networks and information. 


\section{Definition of Terms}

For purposes of this research the following definitions were used.

802.11 - a family of specifications developed by the IEEE in 1997 for wireless local area network technology. 802.11 specifies an over-the-air interface between a wireless client and a base station or between two wireless clients.

$802.11 \mathrm{~b}$ - an extension to 802.11 that applies to wireless LANs and provides 11 Mbps transmission, a 1999 ratification to the original 802.11 standard.

Access Point - a hardware device that acts as a communication hub for users of a wireless device to connect to a wired local area network.

Bandwidth - width of the range of frequencies that an electronic signal occupies on a given transmission medium, expressed as bits of data per second or abbreviated $\underline{\text { bps. }}$.

IEEE - Abbreviation of Institute of Electrical and Electronics Engineers, an organization composed of engineers, scientists, and students. The IEEE is best known for developing standards for the computer and electronics industry.

Legacy systems - computer applications and data that have been inherited from languages, platforms, and techniques earlier than current technology.

Local Area Network - a group of interconnected computers and peripherals that are in the same geographic location, maintained by one group of people, and can be accessed only by members of the group. 
Metric - the measurement of a particular characteristic of a performance or efficiency.

Network Adapter - a communication device installed in a computer so the computer can be connected to a network. Most are designed for a particular type of network, protocol, and media, although some can serve multiple networks.

Radio Frequency - refers to alternating current having characteristics such that, if the current is input to an antenna, an electromagnetic field is generated suitable for wireless broadcasting and/or signal reception.

Reliability - Making sure the network is available to users and responding to hardware and software malfunctions.

Speed - The time response time of network components in transferring files, experessed in Megabits per second (Mbps).

Wireless Local Area Network (Wireless LAN) -- Micro-cellular wireless local area networks layer $802.11 \mathrm{~b}$ standard access points on a wired legacy network that permit the end-user's computer to communicate to any device connected to the legacy network. These wireless networks provide access to intranet as well as Internet resources. The most widely available wireless local area network configuration among institutions of higher education is the microcellular network, and it is the intention of this researcher to define wireless LAN in this fashion. 


\section{CHAPTER II}

\section{Review of Related Literature}

In the last decade, computer networks have been a major focus on college campuses. Network usage by college faculty and students may be a direct effect of the increase in the availability of academic resources in electronic format. The increasing demand for reliable and convenient access to Internet and other digital resources in the support of academic work has resulted in the need to continue to pursue the best medium for ubiquitous access.

\section{Use of Networks for Instruction}

Rather than keeping networked communication activities on the fringe

of the more serious coursework, post-secondary educators are centralizing these activities more integrally in their courses (Campos, Laferriere, and Harasim, 2001). Harasim, Hiltz, Telles, and Turoff (1995) defined learning networks as "groups of people who use computer-mediated communication networks to learn together, at the time, place, or pace that best suit them and is appropriate to the task." In this way networks can offer a built-in support system for the independent learner. The introduction of the Internet and connectivity on campuses has added a new communication channel to the higher education experience. Student inquiry, critical thinking, and problem solving based on information accessed from a variety of sources is an integral part of higher 
education. Computers give students tools for research, data analysis, knowledge application, communication, and collaborative writing (Scardamalia and Bereiter, 1994, 1997).

As new technologies emerge, searching library databases, communicating digitally and participating in electronic activities that support coursework are becoming commonplace on college campuses. A reliable network environment is critical to sustaining these new learning technologies (Manning, 1997). Networks further enrich the learning environment by providing new channels of communication. The networked computer provides unlimited information resources in the classroom and from around the world. Electronic mail facilitates communication among students and faculty, administrators, and the outside world. Electronic student participation in coursework and discussion adds a dimension to the faculty/student relationship as well as adding a new medium for communication (Arduini, 2000; Morton, 1997). Networks provide the channel for students to share documents and resources; to access information from anywhere; to connect with information, resources and people from around the world (Barone and Luker, 2000).

Every year more colleges are equipping students with personal mobile computers, or they are arriving on campus with mobile computers of their own (Brown, 1999; Sargeant, 1997). The combination of networks and mobile computing can have a dramatic affect on the use of information technologies in 
higher education. This pervasive computing environment brings the issue of connectivity to the forefront. The wireless environment allows students to participate in interactive computer events in a classroom, move seamlessly into a laboratory to collect and analyze data, and move once again to a dorm room where the digital library database can be accessed at any time (Brown, 1999).

According to the 2000 user data gathered by the International Center for Computer Enhanced Learning (ICCEL), in order for new technologies to be effective in the classroom, students must consider them integral to the educational process. ICCEL's research supports their principles that collaboration and interaction can be supported and enhanced by the appropriate use of technology. To facilitate the increasing utilization of project collaboration, colleges and universities must develop sound technological infrastructures and strong support programs as well as help faculty understand how and why technology can be helpful in their courses (Campos, Laferriere, and Harasim, 2001).

Campus networks allow students to participate fully in the classroom and access networked class information outside the classroom. On campuses where these technologies have been made available, students show a higher level of comfort with educational technology and use it for many different applications (Holmes and Porter, 1996). The same machine can be used for electronic mail, to run word processing applications, and can be used for a variety of specific 
software applications in the classroom. The computer can be used as an interface among students, between faculty and students and between the college campus and the global community (Fishman, 1996).

Campos et al. (2001) and Alexander (1999) recognized that these learning networks allow students and faculty to learn together in whatever ways they regard appropriate. Electronic learning communities provide limitless possibilities for faculty to plan and promote collaboration in their coursework. Alexander also states that the collaborative network should be used to supplement traditional classroom activities, that online time must be as carefully planned as class time, and that faculty and students require training in these new technologies.

The research that was collected on the Campus Computing Survey by Green between 1996 and 1999 finds that electronic collaboration not only elevates engagement and participation, but also increases thinking and understanding. This network technology enhances the opportunities for continuing the constitutive process by enabling yet another channel for expression of the class content. The Campus Computing Survey also shows higher use of technology on college campuses, making it evident that providing more flexible and accessible electronic resources continues to be an important issue (Greene, 1999, 2000, 2001) 
The TeleLearning Network of Centres of Excellence reports that students are very active in communication electronically, that students report a high peer interaction rate, and those students carry on a more significant amount of the conversation when that conversation is transpiring electronically (Harasim, 1999; Arduini, 2000).

\section{Campus Local Area Networks}

As campuses embark on teaching and learning in the electronic environment of the knowledge age, LANs are more critical to sustaining the teaching and learning process. Access is expected as a standard operating procedure. No longer do colleges view access as a privilege, but as a necessity (Long, 2000). Network plans must take into consideration current infrastructure, existing and emerging networking technologies, and implementation and management of the network traffic patterns.

\section{Wired Infrastructure}

Wired campus infrastructure continues to be important in wireless systems. Many wireless initiatives are layered on legacy wired infrastructure that may or may not have been designed for the addition of the wireless hardware. Though constant change exists, many campus networks are constructed with a set of typical components (Minoli and Alles, 1996). Ethernet is the most widely installed LAN technology. Specified in the IEEE 802.3 standard, Ethernet LAN 
typically uses coaxial cable or special grades of twisted pair wires. Ethernet is also used in support of wireless LANs. There are three types of Ethernet service. The most common Ethernet networks provide transmission speeds up to 10 Megabits per second (Mbps). Fast Ethernet provides transmission speeds up to $100 \mathrm{Mbps}$ and is typically used for LAN backbone systems, supporting workstations with 10BASE-T cards. Gigabit Ethernet provides an even higher level of backbone support at 1,000 megabits per second (1 gigabit or 1 billion bits per second). 10-Gigabit Ethernet provides up to 10 billion bits per second.

Traditional networks of the last ten years and their support and maintenance were fairly straightforward compared to today's available technology solutions. A campus network can be a group of interconnected LANs, the network in a building, or the networks connected between different buildings. From the early 1980s to today, the explosive growth of LANs has been phenomenal (Lynch, 2000).

\section{Wireless Infrastructure}

Wireless LAN products include two components: the access point and the network adapter units. The access point is a radio-based station, which is mounted in a fixed position and is connected to a wired local network. The network adapter unit contains a transmitter, receiver, antenna, and a bridge that routes packets to and from the wired network. 
The network adapter provides the data interface from the access point to the computer; this unit is available in several configurations; PCMCIA compliant is the adapter of choice. The wireless network adapter industry has developed self-regulatory standards administered by the Personal Computer Memory Card International Association (PCMCIA).

The PCMCIA is an international standards body that was founded in 1989. PCMCIA sets standards for Integrated Circuit cards and promote interchangeability among mobile computer manufacturers (PCMCIA, 2002). This PCMCIA device is installed in the same 68 pin connector initially used for memory cards and gives the computer contact to the access point using radio frequency technology.

PCMCIA defined an input/output device as any operation, program, or device that transfers data to or from a computer. Typical input/output devices are printers, hard disks, keyboards, and mice. Some devices are input-only devices such as keyboards; others are primarily output-only devices such as printers, and others provide both input and output of data like hard disks, diskettes, writable CD-ROMs.

The PCMCIA network adapter device serves as both input and output, acting as receiver and transmitter of the radio frequency signal between the computer and the access point (Maughan, 2001). The network adapter is also 
available as a computer chip and internal antenna combination and is included as standard equipment on some personal computers.

Figure 1

Typical Wireless Network

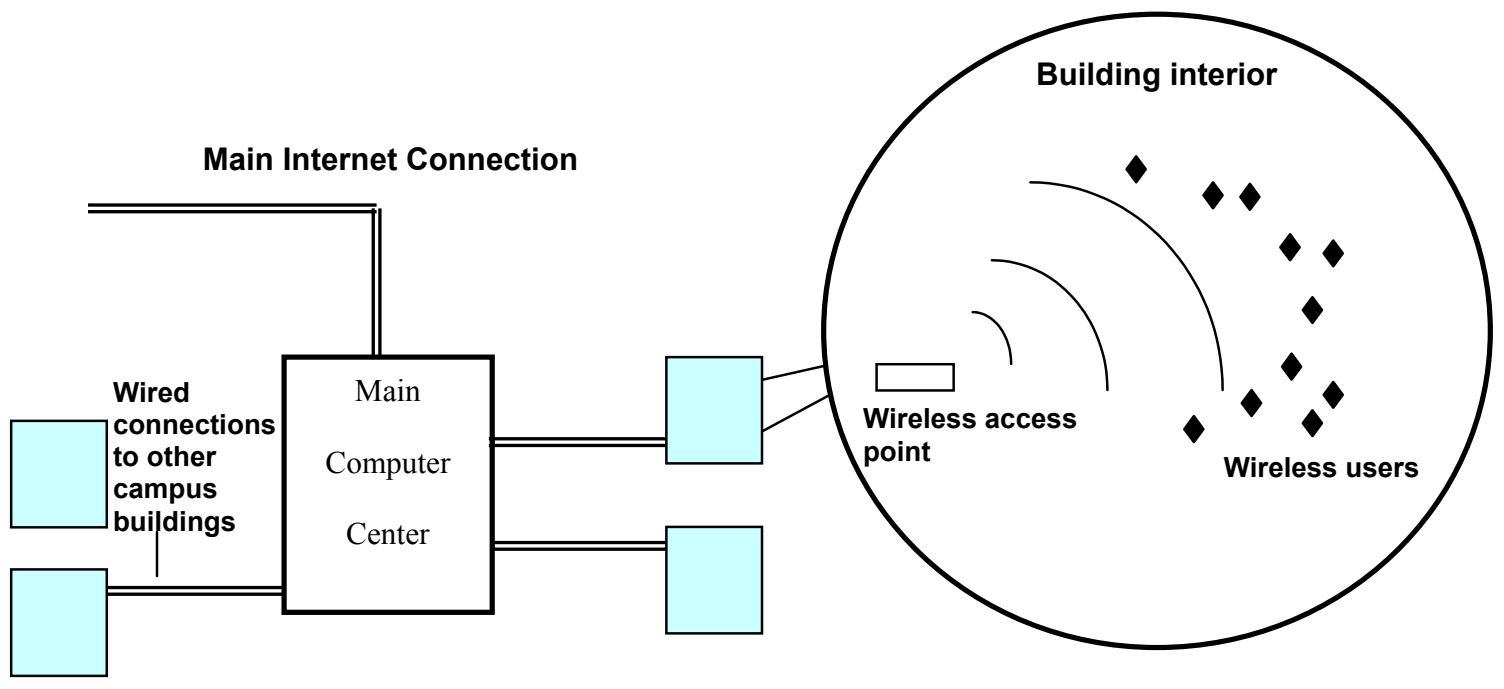

\section{Wireless Planning Considerations}

The wireless LAN design has three main considerations in the planning stage: distance, capacity and cost (Lindgren, 1999). The layout must be based on measurements, not just on "rule of thumb" calculations. These measurements involve extensive testing and careful consideration of radio propagation issues 
when the service area is large, for example, an entire campus as is addressed in this research. Even a very carefully considered access point layout may have to be modified after installation is complete in order to remedy coverage gaps (Garg, 2002).

In the wireless models that are used for wide area coverage, the terrain is an issue to consider. Because the coverage area of the microcellular access point is relatively small, landscape is not a propagation issue. The layout and construction of buildings establish the coverage area of each access point. Wood, plaster, and glass are not serious barriers to the wireless LAN radio transmissions, but brick and concrete walls can be significant barriers. There are many types of barriers to radio frequency signals found in the higher education environment. Not only does the designer need to take account of any sources of electronic interference, but metal is the most commonly found obstacle in office environments. Metal is a prolific building material in higher education, found in desks, filing cabinets, audio-visual equipment and carts, and in reinforced concrete of building foundations (Lindgren, 1999).

The wireless design should also consider the issues of capacity related to application. If many users of mobile computers are located in a small area, students in a classroom or lecture hall, for example, it may be necessary to use multiple access points to provide simultaneous network access to the users. This implies that each access point has a smaller coverage area than might otherwise 
be possible. Applying capacity to application, the network designer must consider the types of applications found in the higher education environment and forecast for those that will likely be deployed in the future (Agrawal and Famolari, 1999). Thus, one would like to carry out a design which is both coverage-oriented and capacity-oriented, assuring adequate service to all users (Langley, 1999).

Network bandwidth that is specific to higher education has two standard of use: (1) standard production software, web surfing and collaborative work will put less traffic and less strain on a network as will the second level of network use; (2) bandwidth-intensive networked multimedia, videoconferencing, video, and imaging. These technologies make existing wired LANs only marginally satisfactory communication platforms (Minoli and Alles, 1996). Traditional college campuses have a foundation in offering residential liberal arts studies. These campuses will continue to offer courses that meet on a regular basis and will support those courses with more electronic information and avail students to the campus LAN (Gilbert, 2000). These emerging technologies support the existence of the traditional space, offering a wireless network layered with a wired network where users can take advantage of the access and freedom of wireless, and when necessary the bandwidth and speed of the wired. There is a middle ground where colleges will find themselves when making technology related decisions. The technology must be progressive enough to stay ahead of 
obsolescence, and it must be cost effective, therefore accessible, in order to see the pervasive use that makes all technologies successful (Brown, 1999).

In the wireless system there are many opportunities for noise generation. The additive noise arises from the components of the system as well as from external sources such as weather, interference from other transmitters, and even electrical appliances. Many researchers have dedicated their work to controlling the noise in the wireless channel and to assure the user that these wireless channels have an acceptable level of security and safety (Hacacute, 1999; Minoli and Alles, 1996; and Varshney and Vetter, 2000). According to Saunders (1999), the common types of noise that are routinely accounted for are reflection from walls and hills, absorption by walls, trees and by the atmosphere, signal scattering from rough surfaces such as the sea, ground and trees, diffraction from edges of rooftops and hilltops, and refraction due to atmospheric layers.

\section{Components of Wireless Campus Networks}

\section{Access Infrastructure Elements}

Determining the efficacy of campus wireless networks requires an analysis of access. Access of wireless systems can be patterned after an infrastructure model developed by Maughan (2001). The elements of the model include devices, networks, skills, economy and policy. Applying this infrastructure model to access on college campuses helps the individual user to "access what they need, 
when they need it" according to Maughan. Applying this model to the access of campus wireless networks will allow us to define the elements of the network and help to determine the metrics with which to evaluate the elements. Devices include those pieces of hardware that allow the end-user to interface with the data systems. The devices include computer components, telephone equipment, and many other devices, which are explained in depth in this chapter.

Devices

In the campus environment, devices serve the role of translator between the technology's internal representation of information and the user's ability to process and perceive this information (LeBlanc and Teal, 1998; McLaughlin, 2001). McLaughlin goes on to identify the common devices found on college campuses as desktop computer, mobile computers, personal digital assistants, telephones, and specialized assistive technologies. The cost of these devices is one of the important metrics in evaluating the efficacy of a wireless LAN. According to Kenneth Green's Campus Computing Survey (1999), a budget model for aging computer equipment is an issue in strategic information technology planning. Recurring investments in technology demands that administrators fund this investment with a planned budget model, not merely with the budget excess from year to year (McCollum, 1999).

Maughan (2001) provides a more exhaustive definition of devices within the information systems infrastructure in higher education. Maughan includes 
telephone handsets or headsets, computer terminals, card swipes, fax machines, satellite uplinks or downlinks, videoconferencing cameras and liquid crystal display (LCD) projectors. As information technology continues to progress to meet the needs of higher education, the devices in the infrastructure change. The convergence of these devices is evident through the past decades. The devices in the information technology infrastructure contain a progression that is evident and based on this trend of technology convergence. The telephone system allowed for voice communication within and from outside the college campus. The facsimile machine was a quickly adopted device on college campuses, allowing users to quickly integrate this new device into their legacy communication systems. With the installation of one device, college campuses could use existing telecommunication lines to now send and receive data transmissions (Manning, 1997; Maughan, 2001).

Card swipes are also a device that allows college campuses to integrate legacy systems and new technologies. The card swipe allows the integration of database technology and communication technology to provide students and faculty with a more secure environment, both physically and electronically. Card swipes are used in small liberal arts colleges for everything from meal counts to convocation attendance.

LCD projectors have provided a revolution in the integration of information technology in the classroom. Previous to this ability to project digital 
information to all students in the classroom, instructional uses were more stunted. The LCD projector is an integral part of the classroom rich with information technology.

Satellite uplinks and downlinks are also devices that many college campuses consider standard equipment. Previous to the emerging trends in distance education, many campuses were broadcasting learning units via satellite transmission, and bringing programming to the campus that would otherwise not have been available. Because of their expense, these technologies are typically found at larger institutions rather than at smaller liberal arts schools.

This trend in systems convergence continues to emerge on college campuses with new and innovative uses for the telecommunication system. Devices began to emerge that would provide an interface between existing databases and communication systems so that users were provided with more sophisticated uses of both the database and the communication system.

The computer terminal as a device is also addressed in the literature. This is another device that has emerged as standard equipment on the college campus, and it has also evolved from just a terminal to the personal computer (Arms, 1988). This device now contains input and output devices, memory, storage, and processing power.

The introduction of a wireless environment impacts the devices that will emerge as common on college campuses. The emergence of the 802.11 standards 
of the IEEE has allowed college administrators to think of devices in a whole new way. Devices in the wired environment are dynamic; the devices may change from day to day, and the location of the devices is also dynamic. College network infrastructure topography now contains a new model. This model includes a device that is introduced to the network, as opposed to a device that the college provides (Long, 2000).

Aside from the end-user computer, the server is a device that is important in the wireless LAN. The server acts as a client for intranet content, applications, and end-user computers. In a campus wireless environment, end-user computers will include a combination of desktop PCs and mobile computers and other Internet client tools such as electronic mail programs, news readers, and streaming video viewers (Bennington and Bartel, 1997; McLaughlin, 2001). Researchers continue to investigate the integrated role of many devices that play an important role in higher education (President's Information Technology Advisory Committee, 2001). Dr. Sherry Manning (1997) has devoted much of her efforts in the effect of telecommunications on college campuses. According to Manning, the Telecommunications Act of 1996 and the deregulation of the industry has opened many opportunities for higher education. With many campus communication systems converging and campuses looking at the integration of Internet resources in teaching and learning, it is increasingly more difficult for colleges to neglect upgrades and service changes in telephony 
(Manning, 1997). In a wireless environment the integration of the LAN, the telephone system and other electronic devices will continue to be an important and dynamic force in the infrastructure model.

\section{Devices specific to Wireless Campus Model}

There are three distinct devices that are important to the wireless campus model: the laptop computer, the wireless access point, and the network adapter. The laptop computer allows the faculty and student to take advantage of the wireless network in a mobile environment. The mobility is a special function of laptop computers that lend themselves well to wireless (Agrawal and Famolari 1999). A mobile computer allows students to move from one place to another and to work in a variety of places (Brown, 1999). The Radio Frequency (RF) technology of the campus wireless system contains two more devices to make the connection.

The wireless networking PC card is the standard device to allow the mobile computer to access the network. The PC card is a credit-card sized removable module that inserts into the mobile computer. It enables high-speed wireless networking at a transmission speed of up to 11 Megabits per second (Mbps). This device comes in a variety of configurations; there is a PC card that interfaces with desktop computers, and several mobile computer models are being manufactured with this device permanently installed as a chip on the system board (Garg, 2002). 
The access point connects the wireless PC card or PC chip to the wired network. These units can be placed inconspicuously anywhere power and a wired network connection exist. The unit sends and receives the radio signal from the computer and communicates with the larger network, intranet, and continuing Internet connection. The wireless access points are installed throughout the coverage area based on the design and measurement of the RF propagation pattern (Saunders, 1999). The access point is the one device in the system that must be planned to integrate in the physical environment. The access point must be located in an area with the provision of an Ethernet connection and sufficient power supply.

There are different antenna options available for the access point. Depending on the layout and design of the network, the number of users served and the strength of the signal, antenna options vary. The access point can be fitted with several different strengths of omni-directional antennas; these are found frequently in wireless outdoor environments (Bennington and Bartel, 2001; Barry, 1998). These omni-directional antenna can be mixed with directional antenna to contain signal within a building; thus increasing the capacity while containing the access. A directional antenna is preferred for making the connection to remote buildings, concentrating the signal and, therefore, increasing the range (Saunders, 1999). 
Networks

Micro-cellular wireless LANs layer 802.11 b standard access points on a wired legacy network that permit the end-user's computer to communicate to any device connected to the legacy network. These wireless networks provide access to Intranet as well as Internet resources. Micro-cellular configurations also permit seamless roaming from cell to cell when the coverage of those cells via access points provides sufficient overlap.

The most widely available wireless LAN configuration among institutions of higher education is the micro-cellular network, and it is the intention of this researcher to define wireless campus network in this fashion. Two main functions of networks in the communication and information infrastructure on a college campus are signal transmission and signal switching (Maughan, Petitto, and McLaughlin, 2001).

Information technology networks facilitate a variety of different activities within a college. The modern campus network facilitates the management and application of enterprise data, student demographic information, as well as transcript and financial information. Enterprise data that is available electronically on the modern campus can realize real-time access for administrators, faculty, and students. This same network will sustain course management software that provides the tools for faculty to create, publish, and manage electronic components of their courses. 
Electronic grade books, on-line quizzes, electronic reserves, chat, and bulletin board services are also typically part of course management software (Gray, 2002). Course management systems have led to the increased availability of electronic portals for the modern campus. Portals provide an on-line web page that is tailored for each individual user. Networks are the backbone of portal technology. Portals allow the user to access just the information that pertains to them.

Portal technology also allows information to be pushed to the user; user group bulletin boards, and individualized information is updated each time the user logs on to the system. Academic portals are built consistent with the same model developed initially by commercial search engines (Gilbert, 2000).

The wires or cables that transmit electronic signals within the network is made of twisted pair cable: thin, multi-strand copper wire that is also found in traditional residential telephone installations, or coaxial cable that provides a higher capacity than twisted pair, or lastly, fiber optic cable made of bundled glass fibers that general light by laser transmission and produce very high transfer rates (Maughan, et al. 2001). This component of the network is imperative to the quality and speed of data transmissions that occur. Bennington and Bartel (1999) regards the configuration of the cable as one good indicator of performance.

Other components of the network are switches, hubs, routers and servers. Though these are pieces of hardware, it is important that they are addressed as 
network components because they are intricate to the efficacy of the network (Minoli and Alles, 1996; Saunders, 1999). These physical pieces of the network ideally serve as throughput devices; they can however restrict access and affect the efficacy of the network. Switches and hubs serve generally the same purpose within the network, however, they differ in the number of users they serve an in their efficiency. A hub serves as a central connection point for network wiring. Hubs cannot establish a direct connection from one computer to another. When a data packet is transmitted from one computer, it actually goes to all of the computers, although only the destination computer receives the data. When large numbers of data packets are moved, hubs slow the network down. In the process of moving data from one computer to another, every computer sees the data, tying up bandwidth. To further slow the network, if two packets enter the network at the same time, the packets collide with each other and need to be retransmitted from the host computer (Saunders, 1999).

Switches are capable of actually switching data from one port directly to another. This faster network performance and fewer errors allow switches to increase network efficacy. Packets can be sent directly from one computer to another without wasting the bandwidth of the entire network attached to that switch.

Switches hold an entire packet in a buffer, determine the destination address, and then route the packet directly to the destination. This switching 
technology saves network bandwidth, since only two computers are involved with the data exchange, instead of all of the computers in the network. The switch also stores this route for future packet transmission; once the packet is exchanged, the future packets are routed directly to their destinations associated now with the designated recipient as each network card has a unique identifier.

Most colleges are still working to provide wired infrastructure that is faster and offers larger bandwidth; the wireless network will still be faced with the issue of bandwidth. The advantage of wireless is in the increased access it affords to the end-user. Barone and Luker (2000) suggest that network should also provide significant convenience and access that meets the academic needs; speed and bandwidth need to be sufficient, but only need to meet the academic. Barone goes on to include many typical academic computing applications where bigger and faster do not necessarily correspond to better. Applications for wireless LAN technology that have already demonstrated success are (1) data access for particularly difficult-to-wire locations including, for example, classrooms, laboratories, and library stacks; (2) data access for wide open spaces, indoors or out and, (3) convenient data access everywhere, for example, across an entire campus (Bennington and Bartel, 2001). The nature of academic work and the wide-scale digitization of literary materials suggests that all colleges and universities are likely to adopt wireless LAN in some locations to meet particular needs, but the research indicates that wireless will not be a substitute for a wired 
infrastructure in the foreseeable future (Barone and Luker, 2000; Cohen, 2000; Hui, Fong, and Lau 2002).

The efficacy of a network in higher education is based on whether or not that network facilitates the traffic of its end-user. The examples cited by Barone above suggest that modest speed and bandwidth can effectively facilitate much of the academic use of the network. Though multimedia files become more widely used in online education environments, intranet activity that is facilitated by a wireless network on a confined campus is composed of much more modest file size, which suggests that traditional transfer rates will continue to be sufficient into the foreseeable future (Harler, 1999).

Wiring is still needed to connect a wireless network access point to the hardwired network. However, from the user's viewpoint, no wires are needed. Every wireless access point using the 802.11 standards needs a wired connection. The access point connects to the wired network via a standard RJ45 Ethernet jack (Saunders, 1999). Wiring for wireless access points requires a different topology than that for traditional wired jacks, so a network mixing both wireless and wired connections may need as much or more wire than before, though with fewer jacks. Wireless networks use hub technology. As stated previously, the bandwidth among hub users is shared. If there are 25 users accessing a single 11MB wireless connection, these 25 users will share the $11 \mathrm{MB}$ of bandwidth. When the $11 \mathrm{MB}$ bandwidth fails due to an abundance of traffic, it does not fail 
proportionally to users, it fails consistently from $11 \mathrm{MB}$ to $5.5 \mathrm{MB}$, to $2 \mathrm{MB}$, to 1 MB, to 0 (Garg, 2002). Shared wired connections today are generally switched, which means that each user has access to the full available bandwidth. Each Ethernet port in the dorm room or classroom has a dedicated $10 \mathrm{MB}$ jack, thus, allowing the user that is plugged into the jack full access to the $10 \mathrm{MB}$. The reliability of wired and wireless technologies can be maximized by familiarity with the type of activity that the network is going to support.

End-users can use the system more effectively if they understand the limitations of the system. For example, a student whose intentions are to watch a streaming video review from a previous class session should be guided toward a wired connection, which allows ample bandwidth on a dedicated 10-megabit switch. Wireless 802.11 networks are an excellent choice for browsing the Web, sending and receiving electronic mail, and carrying out other text-based utilities. Students who want to meet and complete an Internet research project on The Renaissance Period will have all the speed and bandwidth they need on the wireless network and can all connect simultaneously in an area that is equipped with an access point (Brown, Burg, and Dominick, 1998). All of these scenarios are dependent on the student possessing compatible systems hardware; the availability of the hardware will not be addressed in this research. 


\section{Efficacy Evaluation}

Academic literature on the evaluation of networks in campus environments is not proliferate. The literature presented thus far describes in detail how the network is used in the teaching and learning process, the advantages of networks for the end-user, the flexibility and mobility that wireless networks possess, and undeniably the trend that networking and connectedness are an integral part of college campuses; but, how can the network be evaluated for efficacy?

In 1996 the Coalition for Networked Information commissioned a measurement guide titled "Assessing the Academic Networked Environment: Strategies and Options," authored by McClure and Lopata. The metrics for the measurement of campus networks included by McClure and Lopata are users, costs, network traffic, use, network services and support services. The common indicators for evaluation of networks cited by Harasim (1999) are cost, speed, and reliability. The literature established planning benchmarks as distance, capacity and cost (Lindgren, 1999).

Matching the metrics with Maughan's (2001) infrastructure model, one can determine strong indicators for use in self-assessment of the efficacy of campus networks. This research will apply these metrics for the evaluation of wireless campus networks. 
Cost

McClure and Lopata (1996, p.25) define annual information technology expenditures (AITE) as the total amount of money spent by the institution on information technology during one fiscal year. McClure and Lopata go on to define typical IT cost categories. The first category of cost includes system/server hardware. This hardware can be that used for administrative or academic computing for storage or serving data internally or externally.

Communications hardware is another large category of Information Technology expense that McClure and Lopata include in their Technology Expenditures model. Communications hardware on a campus can include communications via telephony, facsimile transmission, and wired or wireless Internet communications. Communications hardware cost is of utmost concern when considering specifically the cost associated with a wireless campus network.

Vendor installation and licensing fees encompass another category of expense. These costs can be closely associated with the category of staffing. Depending on the expertise of staffing positions, there may well be an inverse relationship on staffing costs and vendor installation costs. (Green, 1999).

Licensing costs have to be well researched. Not only is licensing an issue on servers and other college owned resources, but many times in higher education licensing issues are more pressing when applied to equipment that is owned by the student and introduced into the technology environment. The issue of cost of 
licensing now becomes complex as the introduction of equipment may or may not comply with a standard specification. Operating system, memory, installation and upgrade issues all contribute to a functional wireless LAN. McClure and Lopata (1996) also indicates these areas to consider cost estimates within (1) software,(2) training and education, (3) wiring, (4) facilities upgrades and maintenance, (5) content and resource development for network services, (6) program planning and management, (7) and Internet service provider fees.

Research indicates that wireless intranet deployment is not easy and cost savings are not guaranteed. Foundational information technology integration and dealing with the human factor, including training employees are reengineering work processes, are formidable hurdles to achieving the high and rapid return on investment some colleges have sought (Bromley and Jacobsen, 1998; Waugh and Handler, 1998; Lynch, 2000). Researchers observe that as the technology proliferates and continues as an academic necessity, the question of quantifying return on investment will become controversial.

Though financial models vary among institutions, the costs associated with wireless networking must be incorporated into the budget (Antolovic, 2001). Because wireless campus networks are typically layered on top of legacy wired networks, this study will only include costs that are incurred during the installation of the network in a specific area. Comparisons to that of costs will be made between a wired or wireless network that supports network access in a 
given area. It must also be noted that the existence of wireless access allows access in many areas where wired networks cannot feasibly be installed.

There are many ways to interpret the cost of wireless networks. Cost can be equated to actual dollars spent; cost can be formulated by the expense versus the revenue produced, and cost can also be measured in terms of support.

Colleges are spending a significant proportion of their training budget on the direct or indirect costs of on- or off-site seminars and workshops; this cost must be part of a cost-benefit analysis--not only for convenience and availability, but also for the sustainable learning outcomes and how they translate into improved assessment for colleges and universities. While the development costs are fairly high in the short-term, an individualized, readily accessible, effectively designed and executed e-learning plan could increase retention of key learning outcomes and make those training dollars work more directly toward saving cost (Waugh and Handler, 1998).

The physical startup costs for wireless LANs include design, equipment purchase, and installation; ongoing costs include maintenance of the wireless network and user support. Equipment purchases include the wireless access point and antenna. The next cost associated with the wireless network is connecting the wireless network to the campus LAN. The most cost-effective alternative is to connect the access points to an existing LAN; in some cases, colleges may choose to set up a parallel wired network as Carnegie Mellon University has done 
(Bennington and Bartel, 1997). Provision of Ethernet and power wiring to the selected location constituted about one quarter of the overall costs at Carnegie. Speed

When determining the speed of a campus network, researchers have identified constant variables that must be considered. Bennington and Bartel (1999) states the application specifications that are important are (1) file size, (2) type of media, (3) and number of simultaneous users.

Throughput can be measured in a simple comparative manner prior to implementation; it can be more thoroughly investigated as installation proceeds. The classroom situation where a large number of users concentrating on the same application and demanding simultaneous service offers a more accurate throughput analysis (Barry, 1998; Tang and Baker, 2000). The term bandwidth in computer networking refers to the data rate supported by a network connection or interface. Bandwidth is a major indicator of network speed; bandwidth is expressed in terms of bytes per second. Bandwidth represents the capacity of the connection: the greater the capacity, the more data that can be transferred simultaneously (Saunders, 1999). Bandwidth can refer to both actual and theoretical throughput, and it is important to distinguish between the two. For example, a V.90 modem, that provides dial-up Internet service, supports $56 \mathrm{Kbps}$ of peak bandwidth, but due to limitations of the telephone lines and other factors, it is impossible for a home dial-up network to actually achieve this level (Melone 
and Waterman, 1999). An Ethernet network theoretically supports 100 Mbps of bandwidth, but this level can never be achieved in practical use thanks to overhead in the hardware and in the computer's operating system.

Most Ethernet networks use a hub or switch, which serves as the central connection point and moves data around. Like the network adapters, they have three speed ratings: $10 \mathrm{Mb}, 100 \mathrm{Mb}$, and $1000 \mathrm{Mb}$. The switch must support the same speed as your network adapters to use it on your network; most support multiple speeds for this reason. A hub or switch that supports your full range of network adapter speeds will not limit the higher-speed computers.

As stated previously in this research, switches perform more efficiently than hubs in high-traffic networks, therefore, it is a good idea to use a switch if your network will pass data between three or more computers simultaneously. The hub or switch must support your highest network speed to make use of it (Langley, 1999).

The internal computer hardware speed defines the overall speed of the computer whether it is the server or the client machine (Tang and Baker, 2000). The motherboard's processing speed has inherent limits that include network performance. A faster motherboard generally means faster processing, including network performance. Disk performance, defined by Minoli and Alles (1996) as how much information you can read or write from the disk in a second, is often the primary bottleneck to network performance. Since most network data 
represent a file, the hard disk has to read the source file, and another disk must write the file to complete the data transfer. Maximizing disk throughput within the computer will enable marked improvement in speed and reliability (McLaughlin, 2000; Minoli and Alles, 1996).

The wireless adapter also enters as a component in speed. Ethernet's three speeds can be deceptive, since they imply an increase in network speed tenfold by purchasing a faster network adapter; in real tests the performance has been found to range from 100 - 200 kilobytes per second. $100 \mathrm{Mb}$ Ethernet will be 4-6 times faster (not 10), and $1000 \mathrm{Mb}$ a few times faster still, but still not at the increment that the measures imply (Wang and Huey, 1999).

The performance of the network is limited somewhat by outside factors, such as an Internet connection. Small colleges are not always in a situation to leverage high-speed Internet access. Another factor to apply to cost is how much bandwidth to the Internet a small college can afford. The typical limit on an Internet connection is approximately 200 kilobytes, which is easily within the range of a $10 \mathrm{Mb}$ Ethernet network adapter.

A number of tools exist to measure the bandwidth of network connections (Tang and Baker 1999; Tang and Baker 2000). On the Internet, numerous "bandwidth test" or "speed test" programs exist, many made available for interactive use through public Web pages. Anyone who uses these programs quickly learns that bandwidth is a highly variable quantity that is difficult to 
measure precisely. In a nutshell, typical network architectures involve multiple layers hardware and software, as well as time-sharing.

Reliability

The distance over which radio frequency and infrared waves can communicate is a function of product design (including transmitted power and receiver design) and the propagation path, especially in indoor environments. Interactions with typical building objects, including walls, metal, and even people, can affect how energy propagates and, thus, what range and coverage a particular system achieves. Solid objects block infrared signals, which impose additional limitations. Most wireless LAN systems use RF because radio waves can penetrate most indoor walls and obstacles. The range of coverage for typical wireless LAN systems varies from less than 100 feet to more than 300 feet.

\section{Licensing Issues}

In the United States, the Federal Communications Commission (FCC) governs radio transmissions, including those employed in wireless LANs (Melone and Waterman, 1999). Wireless LANs are typically designed to operate in portions of the radio spectrum where the FCC does not require the end-user to purchase a license to use the airwaves. In the U.S. most wireless LANs broadcast over one of the ISM (Instrumentation, Scientific, and Medical) bands. These 
include $902-928 \mathrm{MHz}, 2.4-2.483 \mathrm{GHz}, 5.15-5.35 \mathrm{GHz}$, and 5.725-5.875 GHz (PCMCIA, 2002).

Wireless LANs simplify many of the installation and configuration issues of network managers. Since only the access points of wireless LANs require cabling, network managers are freed from pulling cables for wireless LAN endusers. Lack of cabling also makes moves, adds, and changes trivial operations on wireless LANs. Finally, the portable nature of wireless LANs lets network managers configure and troubleshoot entire networks before installing them at remote locations. Once configured, wireless LANs can be moved from place to place with little or no modification. Wireless connectivity lends itself to the way that students and faculty work on college campuses. Students and faculty who have access to network resources in the library, cafeteria and lounges can begin to employ the full power of information technology (Long, 2000; Brown, 1999). The network is the most important piece of a ubiquitous computing environment, a standard that many campuses are working toward. In this networked model there is intrinsic value to the wireless over the wired environment.

With an increasing use of wireless LANs, it is important to provide decision makers with the information they need to understand and develop these technologies. Metrics to assess wireless networks for small college system administrators do not currently exist. The literature defined cost, speed and 
reliability as the categories of metrics for evaluation of wireless LANs in higher education. The instruments created as part of this research yielded validation of the categories of metrics described in the literature and a self-assessment instrument to guide decision makers at small colleges considering wireless local area network systems. 


\section{CHAPTER III}

\section{Methodology}

In order to conduct this research, the following tasks were performed: (1) identification of the problem, (2) review of literature, (3) creation of the Delphi instrument, (4) identification of the Delphi panel of experts, (5) collection of data, (6) analysis of the data, and (7) drawing of conclusions from the data in order to solve the research problems.

\section{Problem Statement}

The problem of this research is that metrics to assess wireless networks for small college system administrators to use for decision making do not currently exist. This research examined wireless technologies that are available for use in higher education, determined the categories of metrics used to evaluate wireless local area network efficacy, and created an assessment instrument for guiding small college administrators considering wireless local area network systems.

The problem became evident by the lack of academic resources in the area of wireless infrastructure and its impact on the teaching and learning process in higher education. It is recognized that with more evidence, the appropriate use of technology should perpetuate and enhance the teaching and learning process. 


\section{Review of Literature}

Literature was reviewed in the following areas: (1) integration of network computer technology on campuses, (2) local area network designs, (3) campus wireless systems, and (4) the evaluation of the efficacy of wireless networks. This review of literature was compiled using resources available at the West Virginia University Evansdale Library and the West Virginia Wesleyan College Library. On-line electronic resources provided by the West Virginia University and the West Virginia Wesleyan College libraries were also used. The databases included Dissertation Abstracts International, OCLC First Search and Faulkner's Advisory for IT Studies. Several on-line subscription databases were also helpful in locating information in the area of wireless networks; they included the Association of Computer Machinery digital library and the ERIC database. Personal communication with professionals in the field, professional organization proceedings and publications, and government documents also provided supporting information to this research.

\section{Creation of the Modified Delphi Instrument}

The Delphi technique was originally developed to identify and resolve future problems. The Delphi technique is a way of eliciting expert opinion and reaching consensus. According to Whitman (1990) and Smith and Simpson 
(1995) the Delphi characteristics make it an ideal technique for group decisionmaking. Whitman felt that its design facilitates equal expression by all participants. The Delphi method also separates idea generation and idea evaluation, helping to ensure that ideas are not evaluated before multiple options are considered. It is constructed to be content-specific and eliminate time spent considering tangent ideas. The panel of experts completes successive questionnaires over several rounds until consensus is achieved. In some Delphi studies, the study is concluded when the response rate decreases significantly (Martino, 1972).

A modification of the full Delphi Method was used in this research. In the full Delphi method, panelists start off with a blank piece of paper in Round One and create the initial data from their own expertise in the field. This modified study allowed the researcher to collect the initial data from the literature and present it to the panelists. Creating the initial instrument and beginning as if to start with round two made it possible for the researcher to conduct a sequence of rounds and reach consensus.

This research included two instruments. Instrument One allowed the expert panelists to rank the metrics to determine the efficacy of wireless communication systems used for teaching and learning in higher education. The ranked metrics that were identified by the expert panel in Instrument One were used to create Instrument Two, used for self-assessment of the efficacy of 
wireless systems infrastructure in order to answer research question Number 3. Instrument One

Wiersma (1995) states in order for the instrument to be constructed in a straightforward manner, special attention to detail must be given while developing the instrument. The letter of acceptance and all metrics on Instrument One were pilot tested to check for clarity of instructions, clarity of the metric presentation and design of the instrument, proper grammar, and correct spelling.

\section{Instrument One, Importance Ranking of Metrics as Defined by the}

Literature Review, allowed the participants to rate each metric in the categories of cost, speed, and reliability by its level of importance on a five point Likert scale. A Likert scale is a scale with a number of points that provide ordinal scale measurements (Wiersma 1995). The Likert scale used by this researcher was thus: $1=$ important to a small extent, $2=$ fairly important, $3=$ moderately important, 4 = very important, $5=$ extremely important. Asking the expert panel to rank level of importance on a five point Likert scale was modeled after Tigelaar's (2002) data collection instrument. Consecutive rounds of Instrument One would have been implemented for any metrics that did not reach panel consensus during Round one of Instrument One. See instrument in Appendix C. 
Instrument Two

The researcher sent the cover letter, procedures, and self-assessment instrument to the ten panelists who completed Instrument One. An electronic mail message was sent out on the same day giving panelists advance notice that the final instrument in the research project had been returned and also reiterated the date upon which the instrument was to be mailed back. A reminder was sent out to three panelists who had not yet responded after fourteen days. Ten panelists $(100 \%)$ returned the instrument. Appendix B contains the cover letter, procedures, and instrument sent to the panelists.

Detailed instructions were included on the procedures page that accompanied Instrument Two. The instructions stated that the self-assessment instrument included two sections, essential and supplemental information (Stern, 1999). The instructions also stated that Instrument Two was developed directly from the metrics that reached consensus previously in Instrument One. The median ranking of each metric was also included in a column beside each metric on the self-assessment instrument. Within each part of the instrument and within each section, questions were arranged from those the panel ranked most important to those ranked least important.

Instrument Two, Questions decision makers should ask to provide critical self-assessment measure of infrastructure efficacy, was developed directly from the ranked metrics from Instrument One. Instrument Two used a keep, delete, or modify response system. Questions were divided into two sections for the self- 
assessment measure; metrics that received an importance ranking between 3 and 5 on Instrument One were placed in the Essential Information section; and metrics that received an importance ranking of 1 or 2 were placed in the Supplemental Information section. Expert panelists were asked to review each self-assessment question and select "Keep," if the question was interpreted appropriately from the data analysis of Instrument One; "Delete," if the question should be eliminated from the self-assessment instrument, or "Modify" if the question was not interpreted appropriately, and asked for suggestions for question revisions. Questions on the self-assessment instrument reached consensus between $80 \%$ and $100 \%$. Those questions to which the panel recommended modifications were reported in Chapter IV and included in the recommendations for further study.

\section{Identification of Expert Panelists}

An expert was defined as someone who had special knowledge or skill of a particular content area. The literature and standard practice indicated that in the area of wireless networks in higher education, the professionals in product development and manufacturing, in standards development, and system administrators in higher education are working together to facilitate future development. Because of this trend of convergence, two categories of professional experts were identified. In order to retain a panel of at least ten members as recommended by Linstone and Turoff (1979), the researcher identified fifteen original panel members; individuals were selected from two 
categories: college system administrator and manufacturing and development professional.

Higher education administrators who participated in this study were chosen from among the colleges listed in the Yahoo! Internet Life 2001 Most Wired Colleges, Top 50 Small Colleges list. Colleges that were included in the initial pool received a grade of B or higher in wireless access. Colleges who met this criteria were considered wireless pioneers, having access to many academic buildings, and plans to expand coverage to the rest of the campus prior to the fall 2002 semester, or offer wireless access to some buildings on campus, usually including the library and computer center (Bernstein, 2002). Appendix A contains the criteria for Yahoo's rating system.

Administrators from the sixteen eligible colleges then had to meet the following criteria:

(1) hold a Bachelor's degree,

(2) have experience in planning and facilitation of campus Wireless LANs, and

(3) have been published in a peer-reviewed journal, or have at least two year's experience in development, installation, and maintenance of a campus wireless LAN.

Manufacturing and industry panel representatives were employed by wireless companies that were members of the Wireless Ethernet Alliance. The alliance is a nonprofit international association formed in 1999 to certify 
interoperability of wireless Local Area Network products based on IEEE 802.11 specification. Representatives from five companies were identified and asked to participate in the study. The manufacturing and development professional had at least two years experience in working for a wireless vendor who has partnered with college and universities identified as leaders in higher education wireless installations.

Each identified expert was contacted in person by telephone; requests for participation were then e-mailed to the individuals identified above. Participating panel members received a letter thanking them for their willingness to participate in the study that accompanied Instrument One (see Appendix B).

\section{Collection of Data}

The researcher used two instruments. The foundational information and categories for development of Instrument One were identified in the review of literature. In order to identify the level of importance of the categories of metrics for evaluation of the efficacy of a campus wireless system in Instrument One, the modified Delphi technique was selected. Instrument Two was made up of questions that stemmed directly from the importance rankings as identified by the Delphi panel in Instrument One. Instead of following the steps in the pure Delphi method where round one expert panelists develop the questionnaire from their own expertise, the questionnaire was formulated from the information collected 
within the review of literature resulting in the modified Delphi technique (Linstone and Turoff, 1979).

Instrument One

A cover page included directions for completing the survey instrument and for returning the instrument to the researcher. A self-addressed stamped envelope was enclosed with the instrument. Panel members were asked to respond to Likert scale questions and to make any modifications they thought necessary to the descriptive measurements of the metrics that were provided (see Appendix C). A metric was determined to have reached consensus if seventy five percent of the panel rated the level of importance within .5 of the median response of the entire panel. Metrics presented to the panel reached consensus during round 1. These consensus rankings ranged from 1.5 (important to a small extent) to 5 (extremely important.) Because consensus occurred for each metric during round one, the next step in the research process was then to use the range of rankings provided by the panel to create the self-assessment instrument that would be used in the second phase of data collection.

Instrument Two

Panel members received an instrument for use in self-assessment of wireless computer infrastructure on small college campuses. The questions were formulated directly from the metrics generated by Instrument One. Panel members were asked to respond to the specific questions for decision makers with 
a forced-choice "Keep," "Delete," or "Modify," on the appropriateness of the interpretations of the metrics from Instrument One into self-assessment questions in Instrument Two. Questions were grouped based on the level of importance they were given by the panel in Instrument One. Metrics that reached consensus at 3.0 -5.0 were sorted into the Essential Information section of the selfassessment instrument Metrics that reached consensus at a level below 3.0 were placed in the Supplemental Information section of the self-assessment instrument. The complete assessment instrument is contained in Appendix D.

Consensus was defined for Instrument Two when $75 \%$ of the panel agreed that the questions should or should not be included in the self-assessment instrument. Questions that were marked as "Keep" and "Modify" by the panel were tabulated as "accepts" by the researcher. Appendix D reports suggested modifications and interpretation thereof for inclusion in the final self-evaluation.

\section{Data Analysis}

Each round of each instrument was analyzed separately. Data were analyzed to determine measures of central tendency. The median was chosen as the preferred statistic because of its allowance for scores to fall in the upper and lower half of the distribution (Kann, 1999; Stead, 1975).

For the purpose of this study, consensus was reached on Instrument One when $75 \%$ of the panelists rated an item plus or minus .5 of the median rating 
assigned the item by the panel as a whole. Consensus on Instrument Two was reached when $75 \%$ of the panel agreed that the questions should or should not be included in the self-assessment instrument. Dissertation studies by Tigelaar (2002), Kann (1999), and Smith and Simpson (1995) conclude that this was an acceptable percentage to determine consensus in a research study in this field.

\section{Conclusions}

The conclusions of this study were determined by reviewing professional literature and analyzing data collected by both of the modified Delphi instruments. Comparison of those research outcomes to the research questions and problem statement presented in this research granted the researcher the information necessary to draw conclusions from the findings of this research. The research answered each study question, drew inferences from a synthesis of the data, and applied the results to create conclusion statements that answered the problem of this research.

\section{Institutional Review Board}

The researcher and supervising investigator completed the Human Participant Protections Education for Research Teams course prior to collecting data from human subjects. In order to protect the human subjects of research, the College of Human Resources and Education recognizes and follows the review 
procedures and policies of the West Virginia University Institutional Review Board. This research project was exempt from full board review, having met all criteria for exempt status. The project eligibility decision was based on the following:

1. Information was recorded by the investigator in such a manner that human subjects could not be identified.

2. Only responses from participants 18 years of age and older were included.

3. The information requested was non-sensitive in regards to the subject's own behavior.

4. The information did not place any subject at risk for criminal or civil liability if it became known outside the research.

5. Each subject was briefed on the study prior to filling out the survey and was guaranteed anonymity in reporting of the findings. 


\section{CHAPTER IV}

\section{Data Analysis and Findings}

This chapter presents the analysis of data and research findings. The results are reported in three sections: (1) Section one contains results of initiating the study and a profile of the participating panel members; (2) Section two contains the analysis of Instrument One in the modified Delphi study; (3) Section three reports the findings of Instrument Two and the resulting self-assessment instrument.

\section{Panel Members}

Two categories of professional experts were identified. Wireless decision makers in higher education and wireless manufacturing and development industries completed the panel.

Ten higher education wireless decision makers originally agreed to participate in the panel. Those panelists were members of the sixteen colleges that met the criteria of an "A" or "B" rating on the Yahoo Internet Life Magazine Wireless Grade of the 50 most wired small colleges in America (Bernstein, 2002). The researcher attempted to contact all sixteen colleges that met the Yahoo wireless grade criteria. Responsible parties for decision making on wireless systems were reached successfully at $81 \%$ of these colleges. Seventy-seven percent $(77 \%)$ of the remaining thirteen wireless decision makers met the criteria 
of having experience in wireless network planning and implementation in higher education for a minimum of 2 years. Each panelist reported having between 2 and 5 years of experience, possessed a minimum of a Bachelor's Degree, and had presented or published at the regional or national level. For purposes of analysis the 7 higher education administrators and the 3 wireless industry professionals were combined to form one group of experts.

Seventy percent $(70 \%)$ of the original ten higher education representatives returned Instrument One. One panel member requested to be removed from the study based a campus decision to temporarily abandon its wireless efforts; one panel member stated that a college policy restrained her from participating in survey research; and a third panelist made no reply after receiving Instrument One. The participating panel members represented schools with enrollment under 3,000 undergraduate students. Job titles reported on the panelist datasheet supported the panelists' expertise in wireless communication systems in higher education. Higher education decision makers who served on as panelists included professionals with the following job titles: Librarian, Instructional Technologist, Information Technologist, and Chief Information Officer.

Wireless manufacturing and development industries were represented by five expert panelists. Sixty percent $(60 \%)$ of the original five panelists returned the first instrument; one left his position prior to the beginning of the research, one panelist made no contact after receiving the initial instrument. Each 
manufacturing/development panel member held current Certified Wireless Network Professional (CWNP) certification. The CWNP certification was chosen as an indicator of wireless knowledge by vendor experts because it offered the only vendor neutral proctored certification program in the information technology industry.

The CWNP certification certified that successful candidates knew the fundamentals of radio frequency behavior, could describe the features and functions of wireless LAN components, and had the knowledge needed to install, configure, and troubleshoot wireless LAN hardware peripherals and protocols. This certification ensured that panel members had a consistent knowledge base (Siau and Shen, 2003). The specializations stated by the industry representatives were

- Internet Protocol (IP,)

- Telephony,

- Wireless Higher Education Installations,

- Network Security, and 802.11b and 802.11a systems.

Panelists representing the wireless industry represented between 2 and 5 years of experience working with wireless installations in higher education and possessed a minimum of a bachelor's degree. Two of the panelists served as Vice Presidents of major wireless companies; one panel member represented one of the major wireless suppliers in the eastern United States. 


\section{Analysis of Instrument One}

The Round One information packet mailed to panelists contained (1) a letter stating the purpose of the research and thanking each participant for their participation, (2) directions for completing the survey, (3) the professional data sheet, (4) the survey instrument, and (5) a self addressed stamped envelope. Appendix A includes all of the items that were included in this information packet. The panel members were asked to rank from one to five, indicating a level of importance (one representing important to a small extent, five representing extremely important) for each metric identified in the literature as important to wireless communication in higher education.

In addition to responding to the instrument, panel members were also given an opportunity to add metrics to any of the three categories of cost, speed, and reliability. Follow-up electronic mail messages were sent to panel members who had not yet responded on or before the fourteenth day after the first document was mailed. Of the thirteen instruments mailed for round one, ten were returned, resulting in a response rate of $77 \%$. A log was maintained to record the surveys mailed, the number returned and the follow-up that was necessary.

Instrument One contained 3 categories and 27 metrics to be ranked. Instrument One results are displayed in Table 1. Of the 27 metrics in the instrument, five (18\%), were ranked at an extremely high level of importance with a median ranking of 5.00. These five extremely important metrics included 
Cost

- the number of simultaneous users as a metric of cost.

Speed

- the number of simultaneous users as a metric of speed.

Reliability

- 24 hour a day, 7 day a week wireless network access,

- range of the wireless hub, and

- the wireless network's ability to support the software that faculty and students are most likely to use.

Nine metrics $(33 \%)$ in the instrument were ranked at 4.50 or 4.00 (very important) on the rating scale. These 9 metrics, reported by category, were

\section{Cost}

- total cost of installation, and

- cost of securing the wireless network.

Speed

- typical file size the wireless network will transport,

- available bandwidth, and

- the data transfer fate of the supporting wired infrastructure 
Reliability

- range of the network adapter,

- type of building material in the wireless coverage area,

- ability for the wireless network to allow users access to the existing campus network, and

- the ease of user movement from the wired to the wireless environment.

Five metrics $(18 \%)$ were ranked moderately important at 3.5 on the rating scale. By category, those metrics were

Cost

- cost of maintenance of the wireless network.

Speed

- wired and wireless connections supporting the same speed rating,

- use of the most efficient connection technology that available, and

- evaluation of the data transfer rate (Mbps) of the client computers within the wireless network.

Reliability

- determination of the response time of the wireless network support personnel.

Six $(22 \%)$ were ranked fairly important at 2.5 on the rating scale. By category, those metrics were 
Cost

- cost comparison of wired and wireless networks,

- cost of faculty training, and

- cost of new software that will be used in teaching and learning.

Speed

- data transfer rate (Mbps) of the supporting servers, and

- obtaining the fastest wireless network adapters for client computers.

Reliability

- varying operational periods based on typical teaching and learning activities.

Two metrics (7\%) were ranked at important to a small extent at 1.5 on the rating scale; by category, they were

Cost

- calculation of the Return on Investment of a wireless network.

Reliability

- the wireless network only be operational during on-campus course times.

All of the metrics were accepted by the panel and translated into essential and supplemental questions for wireless decision makers in Instrument Two. 
Table 1

Metrics in Wireless Communications in Higher Education, Instrument One

\begin{tabular}{ll}
\hline Metric & $\begin{array}{l}\text { Median } \\
\text { Group } \\
\text { Ranking }\end{array}$ \\
& \\
\hline & \\
COST & 5.0 \\
\hline Number of simultaneous users & 4.5 \\
Total cost of installation & 4.5 \\
Cost of securing the wireless network & 3.5 \\
Cost of wireless network maintenance & 2.5 \\
Cost of wireless vs. wired network costs & 2.5 \\
Cost of training and support for new learning resources & 2.5 \\
Cost of new software & 1.5 \\
Calculation of return on investment & \\
SPEED & 5.0 \\
\hline Number of simultaneous users & 4.5 \\
Typical file transfer size & 4.5 \\
Available bandwidth in support of the wireless network & 4.0 \\
Data transfer rate of the supporting wired infrastructure & \\
Wired and wireless connections supporting the same speed & 3.5 \\
rating & \\
Use of the most efficient connection technology that is & 3.5 \\
available & 3.5 \\
Data transfer rate of the client computer & 2.5 \\
Data transfer rate & 2.5 \\
Obtaining the fastest network adapters for use in client & \\
computers & \\
\hline
\end{tabular}




\section{RELIABILITY}

Operational period 24 hours a day, 7 days a week $\quad 5.0$

Range of the wireless hub $\quad 5.0$

Ability to support the software that faculty and students are most likely to use $\quad 5.0$

Range of the network adapter $\quad 4.5$

Type of building material present in the coverage area $\quad 4.5$

Ability for the wireless network to allow uses access to the existing campus network

Ease of user movement from the wired to the wireless environment

Response time of support personnel

Operational periods varied, driven by typical teaching and learning activities

Operational only during times when on-campus courses are in session

\section{Analysis of Instrument Two}

Instrument Two was created directly from the panel responses to Instrument One. Metrics that were ranked 3.0 or higher corresponded to importance rankings of moderately important to extremely important. Metrics that received an importance ranking below 3.0 on Instrument One, and were considered by the panel to be only fairly important or important to a small extent, were placed in the supplemental information section of Instrument Two. Table 2 illustrates the breakdown of metrics that were ranked essential and supplemental and, therefore, established their placement for Instrument Two. Nineteen metrics were ranked at 3.0 or above; eight metrics were ranked below 3.0 in importance. 
Table 2

Metrics per category ranked Essential or Supplemental by Panel

\begin{tabular}{lcc} 
& \multicolumn{2}{c}{$\underline{\text { Instrument Two Section }}$} \\
Category & Essential & Supplemental \\
\hline Cost & 4 & 4 \\
Speed & 7 & 2 \\
Reliability & 8 & 2
\end{tabular}

In order to create Instrument Two, Questions Decision Makers Should Ask When Planning Wireless Communication Systems in Small Colleges, the metrics from the first instrument were regrouped according to the importance ranking that each metric received from the panel. The categories of cost, speed, and reliability were retained in each section of Instrument Two. The ranked metrics arranged hierarchically within each section can be found in Table 3. The metrics were returned in Instrument Two in the form of a question for self-assessment.

The metrics were also arranged hierarchically within each category when presented to the panel in Instrument Two. The metrics that received the highest importance ranking were, therefore, placed at the top of each category. Instrument Two, see Appendix C, also contained a column that included the importance ranking that resulted from Instrument One; this provided the panel with a report of the results from Instrument One. 
Table 3

Hierarchically Arranged Metrics as Presented in Instrument Two

\begin{tabular}{lc}
\hline Category & Median \\
& Ranking \\
\hline
\end{tabular}

Section I. ESSENTIAL METRICS FOR DECISION MAKING

\begin{tabular}{|c|c|c|}
\hline COST & Number of simultaneous users & 5.0 \\
\hline & Total cost of installation & 4.5 \\
\hline & Cost of securing the wireless network & 4.5 \\
\hline & Cost of wireless network maintenance & 3.5 \\
\hline SPEED & Number of simultaneous users & 5.0 \\
\hline & Typical file transfer size & 4.5 \\
\hline & $\begin{array}{l}\text { Available bandwidth in support of the } \\
\text { wireless network }\end{array}$ & 4.5 \\
\hline & $\begin{array}{l}\text { Data transfer rate of the supporting wired } \\
\text { infrastructure }\end{array}$ & 4.0 \\
\hline & $\begin{array}{l}\text { Wired and wireless connections supporting } \\
\text { the same speed rating }\end{array}$ & 3.5 \\
\hline & $\begin{array}{l}\text { Use of the most efficient connection } \\
\text { technology that is available }\end{array}$ & 3.5 \\
\hline & Data transfer rate of the client computer & 3.5 \\
\hline RELIABILITY & $\begin{array}{l}\text { Operational period } 24 \text { hours a day, } 7 \text { days } \\
\text { a week }\end{array}$ & 5.0 \\
\hline & Range of the wireless hub & 5.0 \\
\hline & $\begin{array}{l}\text { Ability to support the software that faculty } \\
\text { and students are most likely to use }\end{array}$ & 5.0 \\
\hline & Range of the network adapter & 4.5 \\
\hline & $\begin{array}{l}\text { Type of building material present in the } \\
\text { coverage area }\end{array}$ & 4.5 \\
\hline & Ability for the wireless network to allow & \\
\hline & uses access to the existing campus network & 4.5 \\
\hline & $\begin{array}{l}\text { Ease of user movement from the wired to } \\
\text { the wireless environment }\end{array}$ & 4.5 \\
\hline & Response time of support personnel & 3.5 \\
\hline
\end{tabular}


Section II. SUPPLEMENTAL METRICS FOR DECISION MAKING

\begin{tabular}{lll}
\hline COST & Cost of wireless vs. wired network costs & 2.5 \\
& Cost of training and support for new & \\
& learning resources & 2.5 \\
& Cost of new software & 2.5 \\
& Calculation of return on investment & 1.5 \\
SPEED & Data transfer rate & 2.5 \\
& Obtaining the fastest network adapters for & \\
& use in client computers & \\
& & \\
RELIABILITY & Operational periods varied, driven by & 2.5 \\
& typical teaching and learning activities & 1.5 \\
& Operational only during times when on- & \\
& campus courses are in session & \\
& & \\
\hline
\end{tabular}

The results of Instrument Two were analyzed to answer the following research question: What questions should decision makers ask to provide critical self-assessment measures of wireless infrastructure efficacy?

The purpose of the second instrument was for the panel to accept, modify or delete each question for wireless decision makers. Consensus on this instrument confirmed appropriate wording of the self-assessment questions as interpreted from the metrics in Instrument One. The panel was asked to review each self-assessment question and select from among the choices "Keep," "Delete," or "Modify" on the appropriateness of the interpretations of the metrics from Instrument One into self-assessment questions in Instrument Two. 
Items on Instrument Two reached consensus when $75 \%$ of the respondents agreed to either keep or delete the item. Items for which respondents suggested modifications were included by the researcher as an item to keep, and the modifications were recorded and translated into the completed self-assessment instrument. Fifteen items (58\%) on the self-assessment were unanimously accepted by the panel members, six items (23\%) reached consensus at $90 \%$ agreement, and five items (19\%) reached consensus at $80 \%$ agreement. Panelists suggested modifications to $27 \%$ of the twenty seven selfassessment questions on Instrument Two; Appendix D includes a detailed list of these suggestions. These modifications have been interpreted by the researcher and incorporated in the final self-assessment instrument produced by this researcher, also available in Appendix D. 
Table 4

Results of Instrument Two

Section I. Essential Metrics for Decision Making

\begin{tabular}{|c|c|c|c|c|}
\hline Category & Metric & Keep & Modify & Delete \\
\hline \multirow[t]{4}{*}{ COST } & Number of simultaneous users & 10 & 0 & 0 \\
\hline & Total cost of installation & 10 & 0 & 0 \\
\hline & Cost of securing the wireless network & 8 & 2 & 0 \\
\hline & Cost of wireless network maintenance & 10 & 0 & 0 \\
\hline \multirow[t]{7}{*}{ SPEED } & Number of simultaneous users & 9 & 1 & 0 \\
\hline & Typical file transfer size & 9 & 0 & 1 \\
\hline & $\begin{array}{l}\text { Available bandwidth in support of the } \\
\text { wireless network }\end{array}$ & 10 & 0 & 0 \\
\hline & $\begin{array}{l}\text { Data transfer rate of the supporting wired } \\
\text { infrastructure }\end{array}$ & 10 & 0 & 0 \\
\hline & $\begin{array}{l}\text { Wired and wireless connections } \\
\text { supporting the same speed rating }\end{array}$ & 8 & 2 & 0 \\
\hline & $\begin{array}{l}\text { Use of the most efficient connection } \\
\text { technology that is available }\end{array}$ & 10 & 0 & 0 \\
\hline & Data transfer rate of the client computer & 10 & 0 & 0 \\
\hline \multirow[t]{10}{*}{ RELIABILITY } & $\begin{array}{l}\text { Operational period } 24 \text { hours a day, } 7 \\
\text { days a week }\end{array}$ & 9 & 1 & 0 \\
\hline & Range of the wireless hub & 9 & 1 & 0 \\
\hline & $\begin{array}{l}\text { Ability to support the software that } \\
\text { faculty and students are most likely to }\end{array}$ & & & \\
\hline & use & 8 & 0 & 2 \\
\hline & Range of the network adapter & 8 & 1 & 1 \\
\hline & $\begin{array}{l}\text { Type of building material present in the } \\
\text { coverage area }\end{array}$ & 7 & 2 & 1 \\
\hline & $\begin{array}{l}\text { Ability for the wireless network to allow } \\
\text { uses access to the existing campus }\end{array}$ & & & \\
\hline & network & 8 & 0 & 2 \\
\hline & $\begin{array}{l}\text { Ease of user movement from the wired to } \\
\text { the wireless environment }\end{array}$ & 9 & 0 & 1 \\
\hline & Response time of support personnel & 10 & 0 & 0 \\
\hline
\end{tabular}


Section II. Supplemental Metrics for Decision Making

$\begin{array}{llllll}\text { COST } & \text { Cost of wireless vs. wired network costs } & 8 & 0 & 2\end{array}$

Cost of training and support for new

learning resources

Cost of new software

Calculation of return on investment

$9 \quad 0 \quad 1$

$8 \quad 0 \quad 2$

$8 \quad 0 \quad 2$

SPEED

Data transfer rate

9

Obtaining the fastest network adapters

for use in client computers

$10 \quad 0 \quad 0$

RELIABILITY Varied operational periods, driven by typical teaching and learning activities

$10 \quad 0 \quad 0$

Operational only during times when oncampus courses are in session 


\section{CHAPTER V}

Summary, Conclusions, Discussion, Implications, and Recommendations

The purpose of this chapter is to summarize the research, report the conclusions, provide discussion, suggest implications, and offer recommendations for further research. This chapter includes a restatement of the problem and research questions that were addressed by the completion of this research.

\section{Summary}

The efficacy of wireless local area networks in higher education has become a critical issue for administrators and system managers. College administrators and other decision-makers need a set of metrics for evaluating wireless network systems. When college administrators make good decisions about wireless networks, they introduce flexibility and new opportunities into the teaching and learning process. Using the metrics agreed upon the expert panelists, this study has yielded a self-assessment tool that will enable small colleges to assess the efficacy of wireless local area networks on their campuses.

Wireless local area networks are representative of the dynamic technological environment that supports teaching in learning in higher education presently. Panelists were given the opportunity to modify or completely reject the metrics in the second instrument of the study. Though the metrics were categorized into essential and supplemental information, the panel reached a 
consensus that all the metrics will aid decision makers in determining the efficacy of the wireless system. Wireless system decision makers need to know about technology, teaching and learning implications, and campus topology in order to encompass all the information necessary to make good decisions.

\section{Purpose of Study}

The purpose of this research study was to identify and rank the metrics that should be used to determine the efficacy of wireless communication systems in higher education through a modified Delphi method.

The literature indicated that recognized standards exist to aid in the planning of wireless networks; that connectivity on college campuses is prevalent and growing; and that cost, speed, and reliability are important categories of metrics in the evaluation of efficacy of wireless systems. Reliability of network systems plays a major role in their widespread use and efficacy; technology integration is dependent on the reliability of the technology. Decision makers in higher education have a responsibility to make informed decisions about the purchase and deployment of new technologies. Cost and speed of these technologies are essential in putting efficient systems in place. The metrics developed in this study will benefit (1) the teaching and learning process, (2) the wireless decision makers who are responsible for the deployment and evaluation of network systems in higher education, and (3) the wireless industry. 


\section{Problem Statement}

The problem of this research is that metrics to assess wireless networks for small college system administrators to use for decision making do not currently exist. This research examined wireless technologies that are available for use in higher education, determined the categories of metrics used to evaluate wireless local area network efficacy, and created an assessment instrument for guiding small college administrators considering wireless local area network systems.

\section{Methodology}

A modified Delphi technique was used to arrive at consensus among small college administrators and experts in wireless installations in higher education regarding the metrics used to determine the efficacy of wireless communication systems in higher education. In order to conduct this research, the following sequence of procedures was performed: (1) the problem was defined, (2) related literature was reviewed, (3) the Delphi instrument for metric ranking was created, (4) panelists were identified, (5) data were collected, (6) data were analyzed, (7) metrics were interpreted into a self-assessment instrument, (8) a second round of data were collected, (9) data were analyzed, (10) conclusions were drawn from the data , (11) a self-assessment instrument was created, and (12) recommendations were made for further study. 


\section{Research Questions}

The following research questions were addressed.

1. What are the features and benefits of contemporary wireless systems in higher education? The features and benefits of contemporary wireless systems in higher education were identified through a review of the professional literature. Wireless systems in higher education are being used to supplement or extend existing wired networks. These wireless systems integrate not only with the existing campus hardware and software, but also with the hardware and software that the students use in completing their coursework.

2. What are the categories of metrics used to determine the efficacy of the application of wireless campus networks? The research literature defined the categories of cost, speed, and reliability as the foundation necessary for any network system to run efficiently.

3. What questions should decision makers ask to provide critical selfassessment measures of wireless system efficacy? Questions decision makers should ask when determining wireless system efficacy were identified by the researcher and verified by the panel of experts. Based on the initial rank of the metrics in Instrument One, the questions were interpreted by the researcher and were returned to the panel in Instrument Two. The panelists responded whether to keep the questions as presented, modify the question, or recommend the question be deleted from the instrument. Panelist responses were analyzed and 
consensus was reached at a level of $80 \%-100 \%$. Panelists made suggestions for terminology wording on six questions and these suggestions were interpreted for completion of the Self-Assessment Instrument which is contained in Appendix D.

\section{Conclusions}

A review of the professional literature identified the important categories of metrics in evaluating the efficacy of wireless communication systems in higher education. This literature review provided the answer to the first research question. Three distinct categories of metrics important to wireless decision makers emerged from the literature; and the metrics were then presented to a Delphi panel, and their importance level was ranked to answer research question number two. The categories of metrics identified were cost, speed, and reliability. A panel of experts ranked 27 metrics in the three categories as either essential or supplemental information for wireless decision makers in higher education. These metrics were then returned to the panel of experts to validate their translation from metrics to items for self-assessment in order to answer the third research question. Eighteen items were included as essential information for wireless decision makers in the resulting self-assessment instrument. Essential information for wireless decision makers in the category of reliability include the ability to 
- Ensure that the wireless network be operational 24 hours a day, 7 days a week.

- Identify the range of each wireless access points and network adapters (all wireless transmitter/antennas) within the proposed system.

- Identify new hardware and software that the wireless network will make available to faculty and students, and calculate the cost of supporting the new software.

- Identify the type of building materials in the wireless coverage area, and determine if they will affect the wireless signal. Also identify devices that may cause potential interference.

- Identify the software that is necessary for the wireless network user to simultaneously access the legacy/existing campus system.

- Identify the hardware and software that is necessary for the wireless network user to move seamlessly from the wired to the wireless network.

- Determine the response time of support personnel during the operational time of the wireless network.

- Identify the potential number of simultaneous users that the wireless network will support. 
Essential information for wireless decision makers in the category of speed that decision makers should be able to

- Identify the potential number of simultaneous users that the wireless network will support.

- Identify the typical file size that the wireless network will be expected to transport.

- Identify the available bandwidth (on campus and connection to the Internet) that will support the wireless network.

- Identify the data transfer rate (Mbps) of the supporting wired infrastructure.

- Compare the speed rating of the wired connection and the wireless access point to which it connects.

- Identify the most efficient connection technology that is available to support the wireless network.

- Identify the data transfer rate (Mbps) of the client computers within the wireless network.

Essential information for wireless decision makers in the category of cost include the ability to

- Calculate the total cost of installation of the wireless network.

- Calculate the cost of securing the network.

- Calculate the yearly maintenance cost of the wireless network. 
- Calculate any savings the wireless network will produce as a function of networked hardware and software resources (shared software, printers, Ethernet connections, etc...)

Metrics that were ranked as fairly important or important to a small extent were included as optional data collection items for wireless decision makers. The supplemental information established by the modified Delphi panel can be used in creating an investment or use analysis of the wireless system. Supplemental information includes:

- Identification of the times when the wireless network capacity will be at its peak (times when classes will be using the wireless network, or other high use times.)

- Identification of the data transfer rate (Mbps) of the servers that support the wireless system.

- Identification of the speed of the wireless network adapters that you will use in the client computers.

- Comparison of the cost between the installation of a wired and wireless system.

- Calculation of the cost associated with training and support for faculty using new teaching and leaning resources that the wireless network will make available. 
- Calculation of the cost associated with new software the wireless network will make available to faculty and students.

- Calculation of the return on investment of the wireless network.

The efficacy of wireless networks in higher education is complex to calculate. Local network infrastructure including devices, networks, skills, budget and policies must be coordinated with the most up-to-date wireless system components to enable wireless communication that is efficient. The selfassessment instrument is a valuable guide for decision makers, assisting in gathering information specific to the small college environment and in gathering current specifications for wireless network systems. The metrics identified by the researcher offer a timeless guide to wireless system planning. Questions that the assessment poses enable decision makers to find the most up to date information about wireless systems that are available and to match those systems with the appropriate technologies on their own local campuses.

The analysis of information gained from the use of this tool will help ensure that the wireless technologies small colleges are investigating will serve as an integrated part of the teaching and learning process. Wireless systems are evolving rapidly. Radio frequency range, the speed of networks, and the cost of installation and maintenance are just a few examples of areas in wireless system design that will continue to change. Though the specifications change, the 
questions remain the same, and the instrument produced by this research serves as an integral part of planning and implementation process.

In summary, this study found that wireless systems must be easy to use, readily available, and reliable. It is important that the system users have clear and correct information in regards to the nature and the availability of the networks that are in place. Wireless networks allow users to more easily participate in Computer Mediated Communication, allow teachers to plan for classroom events that require all students to be connected to the network, and provide network support for electronic research.

\section{Discussion}

Wireless local area networks first appeared on college campuses as early as 1997. Six years later, the base of the literature in this area continues to show a deficit in assessment of wireless systems specific to small colleges in the United States. This research contributes a set of metrics that can be used to evaluate the efficacy of wireless networks and aid wireless decision makers in providing network resources for small colleges. Wireless networks used in coursework in higher education significantly increase the opportunities for students and faculty members to collaborate (Alexander, 1999; \& Lynch, 2000). The responses from the Delphi panel indicate support of the theory of network use in higher education as a significant part of instruction in higher education today. 
Maughan (2001) presents an infrastructure model that is inclusive of devices, networks, skills, budget and policies. This research supports the theory that no one part of a network can operate efficiently unless all parts of the whole are considered. The panel of experts found the metrics to be very inclusive of all the main theoretical areas of this infrastructure model. The important metrics cover the whole of the campus environment: cost, the ability to install and maintain the wireless system, and components related to the adoption and integration of new hardware and software.

There are many individual components of a wireless system, and it is imperative that all of these components be included in the infrastructure assessment so that the system contains internal integrity. Brown (1999) and Campos, et al (2000) articulate the importance of student equipment. Hardware and software that will be used to interface with the network must remain an important component of assessment procedures so that the system does not merely exist, but that it becomes an integrated part of the teaching and learning process.

Jones, et al (2000) and Young (1999) presented cost, speed, and reliability as the three main categories of metrics important to wireless decision makers. Through this research, the modified Delphi panel concurred with this theory. Cost emerged as a category of metrics necessary to evaluate the efficacy of wireless communication systems in higher education. Small colleges harness 
the power of information technology in whatever way they can afford. Cost is an important metric category because administrators who make decisions concerning wireless networks also have to be conscious of fiscal budgets and both short and long term expenses. Including the consideration of cost in the metrics for decision makers allows them the opportunity to compare wireless products, assess how they will integrate with existing network systems, and how they will fit into long range plans for the institution. The information from the literature and the data collected from expert panelists suggest that there are metrics of cost that are essential to know before embarking on a wireless installation.

Speed was another category of metric that emerged from the literature. Previous researchers and current panel members concurred that the speed of each individual wireless system component is important; however, the most important speed metrics deals with the speed that is necessary to support the applications the network users will be running. Decision makers must take into account how the wireless network will be used, what support is necessary for the wireless network to sustain classroom use, what types of files will be transferred, and how many potential network users there will be. This information will then be synthesized with the speed of the wireless network hardware and software that is available. The researcher found it conclusive that there is not one target speed or bandwidth that is the optimum for wireless campus networks. The optimum speed of the network is dependent on the users of that network. 
Reliability was a category of metric for the evaluation of wireless network efficacy identified in the literature and verified by the expert panel. Overall, there are more metrics associated with reliability than any of the three categories of metrics. In order for the wireless network to be integrated into the teaching and learning environment on a small college campus, both faculty and students need to know where, when, and with what limitations the network will be available to them.

It was established in the literature and verified by the panel on both instruments within this research that reliability is the cornerstone of network efficacy. If a network is not reliable, network use will diminish to an unacceptable level. Reliability in this research exemplifies the availability of the network, the seamless integration of parts of the wireless communication system, and ease of use for the end-user. Regardless of the expense or savings of the installation of a network system, cost is only one of the three important categories of metrics that should be used to evaluate wireless networks. The panel repeatedly validated the importance of speed and reliability of the network in order for the network to be integrated into the teaching and learning process. When decision makers in higher education plan and seek approval for a wireless network solution, it is imperative that the plan consists of all three important areas of wireless efficacy evaluation: cost, speed, and reliability. 
Panel members included several remarks during both rounds of the research indicating that reliability is the best measure of network efficacy. The following comments relate directly to the reliability of the wireless network.

- "Without reliability, who would use it?"

- "The network has to be up, regardless of price or speed; if it isn't reliable, forget it!"

- "Reliability is the only important thing to the user; they may complain about speed, and will be unaware of the cost."

- "The administrators have to be convinced that the cost is within reason. The users want to see speed on our wireless network that mirrors the wired connections. Reliability is our number one priority; our users have to trust that when they need to connect, they can." There were eight reliability metrics that were ranked at 3.0 or above on Instrument One; four speed metrics that were ranked as "essential"; and only four cost metrics were included in the essential section of the self-evaluation instrument.

The research supports the diversified infrastructure model proposed by Maughan (2001). Wireless network infrastructure includes much more than equipment. Panelists within this study confirm the findings of the literature by attaining consensus on all the metrics that were reported in the literature. 
Panelists suggested modifications to the metrics but did not recommend the inclusion of other metrics or the deletion of any metric that was presented.

Panelist comments on the changing cost structure of wireless technology also necessitate discussion in terms of this and further research. Two panelists commented that wireless networks may cost less than the wired networks they replace. Panelists stated

- "Schools are actively moving away from main wire lined networks to wireless networks due to "Total Cost" reduction.

- "Consider the freedom of mobility and its effect on operational cost savings."

- "Wireless is an extension of wired networks. In a high percentage of cases, the cost should be identical as wired. Some cases wireless networks should lower operations and that saves money."

Panelists also commented that because wireless networks can connect areas that cannot be connected by wired connections, it is difficult to compare the cost of the two different technologies. These observations suggest that the ways in which technology is used in teaching and learning is changing because of the access to information that wireless communication systems permit. When planning for wireless campus networks, it is important to know how the network 
will be used. It is equally important in this dynamic technological environment to be able to forecast potential activities the wireless technology will support.

\section{Implications}

The metrics to evaluate efficacy of wireless systems in higher education were established in the literature, confirmed by the modified Delphi panel, and interpreted by the researcher. The metrics reported in this research are common elements of a network; they are central constructs that are unchanging in the wireless system. The final product of this research was a self-assessment instrument to evaluate the efficacy of wireless systems in higher education. Table 5 contains the final self-assessment data for decision makers to collect in order to assess their wireless LAN.

The self-assessment instrument contains two major sections: essential information and supplemental information. The essential information is divided further into three parts: reliability, speed, and cost. Section One focuses on the information that it is essential to collect in order to make good decisions about the wireless system that will best compliment existing infrastructure. Decision makers should record the information that correlates to each question in Section One. This information can then be used to determine the specifications that the wireless system installation must meet. Collection of the supplemental information is optional for the wireless system decision maker. The supplemental 
information may be beneficial in creating an investment or use analysis of the wireless system.

Table 5

A Self-Assessment Instrument: Questions Decision Makers Should Ask When Planning Wireless Communication Systems in Small Colleges

Section One. Essential Information

PART ONE. RELIABILITY

1. Can you ensure that the wireless network be operational 24 hours a day, 7 days a week?

2. Identify the range of each wireless access points and network adapters (all wireless transmitter/antennas) within the proposed system.

3. Identify new hardware and software that the wireless network will make available to faculty and students, and calculate the cost of supporting the new software.

4. Identify the type of building materials in the wireless coverage area, and determine if they will affect the wireless signal. Also identify devices that may cause potential interference.

5. Identify the software that is necessary for the wireless network user to simultaneously access the legacy/existing campus system.

6. Identify the hardware and software that is necessary for the wireless network user to move seamlessly from the wired to the wireless network.

7. Determine the response time of support personnel during the operational time of the wireless network. 


\section{PART TWO. SPEED}

1. Identify the potential number of simultaneous users that the wireless network will support.

2. Identify the typical file size that the wireless network will be expected to transport.

3. Identify the available bandwidth (on campus and connection to the Internet) that will support the wireless network.

4. Identify the data transfer rate (Mbps) of the supporting wired infrastructure.

5. Compare the speed rating of the wired connection and the wireless access point to which it connects.

6. Identify the most efficient connection technology that is available to support the wireless network.

7. Identify the data transfer rate (Mbps) of the client computers within the wireless network.

\section{PART THREE. COST}

1. Calculate the number of users who will access the wireless network simultaneously.

2. Calculate the total cost of installation of the wireless network.

3. Calculate the cost of securing the network.

4. Calculate the yearly maintenance cost of the wireless network.

5. Calculate any savings the wireless network will produce as a function of networked hardware and software resources (shared software, printers, Ethernet connections, etc...) 
Section Two. Supplemental Information

1. Identify the times when the wireless network capacity will be at its peak (times when classes will be using the wireless network, or other high use times.)

2. Identify the data transfer rate (Mbps) of the servers that support the wireless system.

3. Identify the speed of the wireless network adapters that you will use in the client computers.

4. Compare the cost between the installation of a wired and wireless system.

5. Calculate the cost associated with training and support for faculty using new teaching and leaning resources that the wireless network will make available.

6. Calculate the cost associated with new software the wireless network will make available to faculty and students.

7. Calculate the return on investment of the wireless network.

To successfully evaluate and implement efficient wireless systems in higher education, wireless decision makers must apply these metrics early and often. Wireless systems are constantly evolving; network standards and protocol are continually updated, and the computer hardware and software industry is one of planned obsolescence. These dynamic features of wireless technology demand that decision makers continually evaluate their wireless campus networks. Identification of the metrics to evaluate efficacy adds significantly to the research in the field of wireless systems in higher education. 


\section{Recommendations for Further Research}

Based on the information generated by this research project, this

researcher recommends that further research should be conducted to

1. Study the use of cellular telephony by college students and explore the wireless computer channels that this technology will introduce to the campus.

2. Study the impact that wireless communication systems have on learning in different higher education situations; content areas, class sizes, teaching methods, student computing models.

3. Information technology changes at a very rapid pace; as wireless systems mature, researchers should track the installation and impact of wireless communication systems in higher education.

4. Wireless computer networks are a dynamic part of the information technology industry. As new standards are set and new technologies are developed, those new developments should be studied for their impact on present and future applications in higher education.

5. Duplicate this research study when more small colleges have implemented wireless LANs and, therefore, there will be a larger number of expert panelists available to participate.

6. Validate the self-assessment instrument that was the product of this research. 


\section{REFERENCES}

Agrawal, P. and Famolari, D. (1999) Mobile computing in next generation wireless networks. Proceedings of the 3rd international workshop on Discrete algorithms and methods for mobile computing and communications. Seattle, Washington, United States.

Alexander, J. O. (1999). Collaborative design, constructivist learning, information technology immersion and electronic communities: A case study. Interpersonal Computing and Technology Journal, 7, (nr 1-2). Retrieved from_http://www2.nau.edu/`ipct-j/1999/n1-2/alexander.html

Antolovic, L. G. (2001). Budget. Technology leadership: Communication and information systems in higher education. Maughan, G., (Ed.) San Francisco: Jossey-Bass.

Arduini, T. L., (2000). Interpersonal communication motives and channel selection: An investigation of student-to-teacher out-of-class communication (Doctoral dissertation, Southern Illinois University of Carbondale). Dissertation Abstracts International, 61, 2991.

Barone, C. A., \& Luker, M. A. (2000) The role of advanced networks in the education of the future. Preparing your campus for a networked future. Lukar, M. (Ed.). San Francisco: Jossey-Bass. 
Atkins, M.J. (1993). Evaluating Interactive Technologies for Learning. Journal of Curriculum Studies, 26(4), 333-342.

Barry, G. J. (1998). The wireless network at Drexel: A study. Retrieved from http://inside.drexel.edu/networking/wireless/.

Bennington, B. J., \& Bartel, C. R. (2001) Wireless Andrew: building a high speed, campus-wide wireless data network. Mobile Networks and Applications, 6(1), 9-22.

Bennington, B.J. \& C.R. Bartel, (1997). Wireless Andrew: Experience Building a High Speed, Campus-Wide Wireless Data Network. Third Annual ACM/IEEE International Conference on Mobile Computing and Networking, Budapest, Hungary.

Bernstein, R. (2002). 2001 Final List of 50 Top Small Colleges and Wireless Grade. Yahoo! Internet Life, 8 (3). Retrieved from http://www.zdnet.com/zdsubs/yahoo/content/100mostwired/

Bromley, H. \& Jacobson, S. L. (1998). Technology and change in school administrator preparation. Technology and the Educational Workplace. Westbrook, K., (Ed.) Thousand Oaks, CA: Sage.

Brooks, M. G., \& Brooks, J. G. (1999). The courage to be constructivist. Educational Leadership. 57(3), pp 27-36.

Brown, D (Ed.). (1999) Interactive Learning: Vignettes from America's Most 
Wired Campuses. Bolton, MA: Anker.

Brown, D., Burg, J. J., \& Dominick, J. L. (1998). A strategic plan for laptop computing. Communications of the ACM. 41(1), 26-35.

Campos, M., Laferriere, T., \& Harasim, L. (2001). The Post-Secondary Networked Classroom: Renewal of Teaching Practices and Social Interaction. Journal of Asynchronous Learning Networks, 5(2). Retrieved from http://www.aln.org/publications/jaln/v5n2/v5n2_campos.asp\#14.

Cohen, J. (2000). Wireless networking: What role will it play in your campus's future? Proceedings of the Educause National Conference, USA, 00, 7487.

Fishman, B. (1996). High-End High School Communication: Tool Use Practices of Students in a Networked Environment. . (Doctoral dissertation, Northwestern University, IL. Dissertation Abstracts International, 57, 2446.

Garg, V. K. (2002). Wireless Network Evolution: 2G to 3G. Chicago, IL: Prentice Hal, PTR.

Gilbert, S. W. (2000). Portal Decisions Demand Collaboration - Can Portals Support It? Syllabus, 13(2) 1-3.

Gray, S. (2002). A moving target: eLearning vendors take aim in a changing environment. Syllabus, 15(8) 34-42. 
Green, K. (2001). The Campus Computing Project. Retrieved from http://www.campuscomputing.net/summaries/2001/.

Green, K. (2000). The Campus Computing Project. Retrieved from http://www.campuscomputing.net/summaries/2000/.

Green, K. (1999). The Campus Computing Project. Retrieved from http://www.campuscomputing.net/summaries/1999/.

Hacacute, A. (1999). Congestion control in a wireless network. International Journal of Network Management, 9(3), 185-192.

Harasim, L., Hiltz, S.R., Teles, L., \& Turoff, M. (1995). A Field Guide to Teaching and Learning Online: Learning Networks, USA, MIT Press

Harasim, L. M. (1999). A framework for online learning: The Virtual-U. IEEE Computer., 32(9), 44-49.

Harler, C. (1999). Colleges take to the air. Journal of Telecommunications in Higher Education, 3 (4), 12-17.

Holmes, M. \& Porter, D. (1996). Student Notebook Computers in Studio Courses. Proceedings of ED-MEDIA 96. Boston: AACE.

Holleque, K. \& Cartwright G. P. (1997). Assessing the Notebook Initiative. Change, 29(6), pp 10-12.

Hui, S. C., Fong, A. C. M., \& Lau, C.T. (2002). Unified personal mobile communication services for a wireless campus. Campus-Wide Information Systems, 19,(1), 27-35. 
Iroff, L., \& Sawhill, B. (2000). Implementing and supporting a wireless classroom. Proceedings of the Conference on User Services: Building the Future, USA, 2000, 125-126.

Jones, M. L. W., Rieger, R. H., Treadwell, P., \& Gay, G. K. (2000). Live from the stacks: User feedback on mobile computers and wireless tools for library patrons. Proceedings of the ACM conference on digital libraries, USA, 5, $95-102$.

Kann, C. H. (1999). A study to identify operational computer lab models and to develop an instrument to assist in evaluating programs that provide computer technology to accommodate needs of students with disabilities in higher education (Doctoral dissertation, West Virginia University, 1999). Dissertation Abstracts International, 62, 39.

Kovac, R. \& Jones, S. (1999). Wireless LANSs: Coming to a campus near you? Journal of Telecommunications in Higher Education, 3 (4), 18-22.

Langley, J. (1999). Moving wireless LANs into fast lane. Network World, 16(6), $31-33$.

LeBlanc, R. J. \& Teal, S. L. (1998). Hardware and software choices for student computer initiatives. Communications of the ACM, 4l(1), 64-69.

Laurillard, D. (1978). Evaluation of Student Learning in CAL. Computers and Education, 2, 259-265. 
Lee, C. H. (1999). An Exploration of Pedagogical Implications of Using Network-Based Computer Mediated Communication in the Communicative Language Classroom. Interpersonal Computing and Technology Journal 7, (nr 1-2) Retrieved from http://www2.nau,edu/'ipet-j/1999/n1-2/Lee.html.

Lindgren, L. (1999). Going wireless for last-mile connectivity. Journal of Telecommunications in Higher Education, 3 (4), 22-26.

Linstone, H. \& Turoff, M. (1979). The Delphi method: Techniques and applications. Reading: MA. Addison-Wesley Publishing Company.

Long, P. E. (2000). Planning, designing, and growing a campus network for the future. Preparing your campus for a networked future. Lukar, M. (Ed.). San Francisco: Jossey-Bass.

Luker, M. A. (Ed.) (2000). Preparing your campus for a networked future. San Francisco: Jossey-Bass.

Lynch, C. A. (2000). The academic library in the networked information age. Preparing your campus for a networked future. Lukar, M. (Ed.). San Francisco: Jossey-Bass.

Lysiak, F., Wallace, S., and Evans, C. (1976). Computer-assisted instruction 1975-76 evaluation report. Eric Ed, 140-495.

Manning, S. (1997). Telecommunications and Higher Education: Issues, Opportunities, and Applications. Chareleston WV: ECCI Press. 
Martino, J. (1972). Technological Forecasting for Decisionmaking. New York: NY: American Elsevier Publishing Company.

Maughan, G. (Ed) (2001). Technology leadership: Communication and information systems in higher education. San Francisco: Jossey-Bass.

Maughan, G., Petitto, K. R., \& McLaughlin, D. (2001). Networks. Technology leadership: Communication and information systems in higher education. Maughan, G., (Ed.) San Francisco: Jossey-Bass.

McLaughlin, D. (2001). Information technology user devices in higher education. Technology leadership: Communication and information systems in higher education. Maughan, G., (Ed.) San Francisco: Jossey-Bass.

Melone \& Waterman. (1999). Interview with Bell-Atlantic, a leader in wireless technologies, two insiders share their insights. Journal of Telecommunications in Higher Education, 3 (4), 30 -33.

McClure, C. R. \& Lopata, C.L. (1996). Assessing the Academic Netowrked Enfironment: Strategies and Options. Washington, D.C., Association of Research Libraries.

McCollum, K. (1999) Colleges Struggle to Manage Technology's Rising Costs. The Chronicle of Higher Education, 45(24), 27-29.

McGinity, M. (1999). Staying connected: Flying wireless, with a net. Communications of the ACM, 42(12), 19-21. 
McKenzie, Ross A. (1999). Wireless Laptop Computing: A new direction in Student Computing. Paper presented at CUMREC '99, The College and University Information Services Conference, sponsored by Educause.

Minoli, D., \& Alles, A. (1996). LAN, ATM, and LAN Emulation Technologies. Boston: Artech House.

Morton, J. F. (1997). The effect of computer-mediated communication on facultystudent interaction. Unpublished doctoral dissertation, University of Hawaii, Manoa.

Oblinger, D., \& Rush, S. C. (Eds.). (1997). Future compatible campus planning, designing and implementing information: Planning, designing, and implementing information technology in the academy. Bolton, MA: Anker Publishing Company, Inc.

PCMCIA. (2002). Mission statement and strategic objectives. Personal Computer Memory Card International Association. Retrieved from http://pcmcia.org/mission.htm.

President's Information Technology Advisory Committee (2001). Using Information Technology To Transform the Way We Learn. Report to the President. Washington, D.C.

Sargeant, D. (1997). Moving Toward a Mobile Teaching and Learning Environment: Using Notebook Computers. The Learning Revolution: The 
Challenge of Information Technology in the Academy. Oblinger, D. G. and Rush, S. C., (Eds.) Anker Publishing, Bolton, Mass., 74-91.

Saunders, S. R. (1999). Antennas and Propagation for Wireless Communication Systems. Chichester, UK: Wiley.

Scardamalia, M. \& Bereiter, C. (1997) Student communities for the advancement of knowledge. Communications of the ACM, 39(4), 36-37.

Scardamalia, M. \& Bereiter, C. (1994) Computer support for knowledge-building communities. The Journal of the Learning Sciences, 3(3), 265-283.

Siau, K., \& Shen, Z. (2003) Building customer trust in mobile commerce. Communications of the ACM, 46 (4), 91-94.

Smith, K. S., \& Simpson, R. D. (1995). Validating teaching competencies for faculty members in higher education: a national study using the Delphi method. Innovative Higher Education, 19(3), 223-234.

Stallings, W. (1997). Local and metropolitan area networks. Upper Saddle River, NJ: Prentice Hall.

Stead, F. L. (1975). An Application of the Delphi Method of Forecasting to Nursing Education Planning in West Virginia. (Doctoral dissertation, West Virginia University; 1975). Dissertation Abstracts International, 36, 3312.

Stern, G. (1999). The Drucker Foundation Self-Assessment Tool Process Guide. Jossey-Bass, San Francisco, CA. 
Tang, D., \& Baker, M. (1999). Analysis of a metropolitan-area wireless network. Proceedings of the ACM/IEEE International Conference on Mobile Computing and Networking, USA, 5, 13-23.

Tang, D., \& Baker, M. (2000). Analysis of a local-area wireless network. Proceedings of the ACM/IEEE International Conference on Mobile Computing and Networking, USA, 6, 1-10.

Tigelaar, D. H. (2002). The development and validation of a framework for teaching competencies in higher education. Unpublished doctoral dissertation, University of Maastricht, The Netherlands.

Varshney, U. (1999). Networking support for mobile computing. Communications of the Association for Information Systems, 1 (1), 2-26.

Varshney, U., \& Vetter, R. (2000). Emerging mobile and wireless networks. Communications of the ACM, 43(6), 73-81.

Wang, K., \& Huey, J. (1999). A cost effective distributed location management strategy for wireless networks. Wireless Networks, 5(4), 287-297.

Waugh, M. L. \& Handler, M. (1998). Preparing teachers to teach with technology: The costs and benefits of developing an electronic community of learners. Technology and the Educational Workplace. Westbrook, K., (Ed.) Thousand Oaks, CA: Sage.

Wiersma, W. (1995). Research Methods in Education. An Introduction. Ed. $6^{\text {th }}$. Allyn and Bacon, Boston, MA. 
Whitman, N. I. (1990). The Delphi Technique as an Alternative for Committee Meetings. Journal of Nursing Education, 29 (8), 377-379.

Young, J. (1999). Learning to learn: Assessing information technology literacy. Inventio 1, (2). Retrieved from http://www.doit.gmu.edu/Archives/Oct99/jyoung_9.htm. 


\section{APPENDIX A}

\section{Wireless Campus Selection}

\section{Exhibit A1}

Yahoo! Internet Life 2001 Final List of 50 Top Small Colleges and

Wireless Grade (Bernstein, 2002).

\begin{tabular}{|c|c|c|}
\hline 导 & 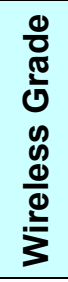 & 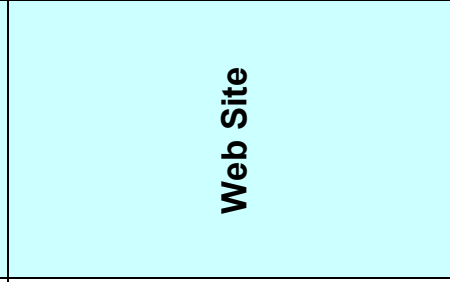 \\
\hline Williams College & $\mathrm{B}+$ & www.williams.edu \\
\hline Stevens Institute of Technology & A & http://www.stevens-tech.edu \\
\hline Wellesley College & C- & www.wellesley.edu \\
\hline Worcester Polytechnic Institute & $\mathrm{B}+$ & http://www.wpi.edu/ \\
\hline Colby College & D- & www.colby.edu \\
\hline Loyola University New Orleans & C- & http://www.loyno.edu \\
\hline Albion College & $\mathrm{C}$ & http://www.albion.edu \\
\hline Valley City State University & $\mathrm{D}$ & http://www.vcsu.edu \\
\hline Buena Vista University & A & http://www.bvu.edu \\
\hline Swarthmore College & $\mathrm{D}+$ & www.swarthmore.edu \\
\hline Gettysburg College & $\mathrm{B}+$ & http://www.gettysburg.edu \\
\hline Washington and Lee University & $\mathrm{C}+$ & www.wlu.edu \\
\hline College of Saint Benedict & $\mathrm{C}$ & http://www.csbsju.edu \\
\hline Union College & B- & www.union.edu \\
\hline Smith College & B- & www.smith.edu \\
\hline University of Minnesota, Crookston & C- & http://www.crk.umn.edu \\
\hline Brandeis University & $\mathrm{D}$ & http://www.brandeis.edu \\
\hline University of Missouri\&-Rolla & $\mathrm{B}$ & http://www.umr.edu \\
\hline Albertson College of Idaho & A & http://www.albertson.edu \\
\hline Wesleyan University & C- & www.wesleyan.edu \\
\hline Whitman College & $\mathrm{C}-$ & www.whitman.edu \\
\hline University of Richmond & $\mathrm{D}$ & http://www.richmond.edu \\
\hline College of Mount St. Joseph & A & http://www.msj.edu \\
\hline Shenandoah University & $\mathrm{B}+$ & http://www.su.edu \\
\hline Pacific University & $\mathrm{F}$ & http://www.pacificu.edu \\
\hline
\end{tabular}


Exhibit A1, cont.

\begin{tabular}{|l|c|l|}
\hline Chapman University & B & http://www.chapman.edu \\
\hline Skidmore College & D+ & www.skidmore.edu \\
\hline Bowdoin College & C- & http://www.bowdoin.edu \\
\hline Sweet Briar College & B- & http://www.sbc.edu \\
\hline La Salle University & D & http://www.lasalle.edu \\
\hline Walsh University & B+ & http://www.walsh.edu \\
\hline Vassar College & A- & www.vassar.edu \\
\hline The Catholic University of America & C- & http://www.cua.edu/ \\
\hline Illinois Institute of Technology & D & http://www.iit.edu \\
\hline Bucknell University & C- & www.bucknell.edu \\
\hline Hamilton College & C- & www.hamilton.edu \\
\hline Oberlin College & C+ & www.oberlin.edu \\
\hline Jacksonville University & C & http://www.ju.edu \\
\hline Colgate University & D+ & http://colgate university \\
\hline Drury University & D+ & http://www.drury.edu \\
\hline Longwood College & F & http://www.lwc.edu \\
\hline Mount Holyoke College & D+ & www.mtholyoke.edu \\
\hline Millikin University & F & http://www.millikin.edu \\
\hline Concordia University & F & http://www.csp.edu \\
\hline Susquehanna University & D- & http://www.susqu.edu \\
\hline Cedarville University & D- & http://www.cedarville.edu \\
\hline Bryant College & F & http://www.bryant.edu \\
\hline Johnson C. Smith University & F & http://www.jcsu.edu \\
\hline Adelphi University & D+ & http://adelphi.edu \\
\hline Nebraska Wesleyan University & B+ & http://www.nebrwesleyan.edu \\
\hline
\end{tabular}




\section{$\underline{\text { Exhibit A2 }}$}

Yahoo! Internet Life Most Wired Colleges Grade Scale for Wireless Access

\section{Wireless Access}

While most major university and colleges offer high-speed Net access in dorm rooms, only a select few have rolled out wireless networks. Though this category counted the least in our rankings, it's a good indicator of whether a school is an early adopter of new technologies.

Major Factors: Availability of wireless data networking to institution buildings and grounds, including on-campus housing and academic buildings

Grades

A. The school is a wireless pioneer; access is already available in many academic buildings, and plans are in place to expand coverage to the rest of the campus this year.

B. Some buildings on campus offer wireless access; these usually included the library and computer center.

C. Trial-only, folks. The school has just begun to test the wireless waters, and a few lucky students may get to play beta-tester.

D. Mired in wires: The school has no plans to develop a wireless networks before the fall 2002 semester. 


\title{
APPENDIX B
}

\section{Instrument One}

\author{
Exhibit B1
}

Participant Accept Letter to Accompany Instrument One

Dear [Panel Member],

Thank you for agreeing to participate as a panel member for my dissertation research entitled, Identification of Metrics Used to determine the Efficacy of Wireless Communication Systems in Higher Education; as partial fulfillment for the doctoral degree from the Technology Education Department at West Virginia University. The research will use a modified Delphi method to (1) determine the level of importance of the metrics used to determine the efficacy of wireless systems as defined in the literature and (2) define the critical questions for decision makers in the self-assessment measures of infrastructure efficacy.

The panel will be comprised of 12-15 members who are experts in wireless systems on small college campuses and vendors who have expertise in supporting wireless systems at institutions of higher education.

The results of this research will assist decision makers in small colleges to determine the efficacy of wireless systems on their campuses.

You will be asked to respond to a series of two instruments. Your responses will remain anonymous and confidential. You may choose not to respond to any item. Your participation in the study is voluntary. Final results of the study will be reported to the participants at the end of the study.

Please complete the enclosed data sheet or include a current resume or vita when you return Instrument \#1 in the self-addressed, stamped envelope that has been provided. Another alternative for return is to fax the personal information and Instrument \#1 to me. My fax number is 304-473-8181. I look forward to receiving your responses.

If you have any questions concerning this research, please contact me immediately. My e-mail address is petitto@wvwc.edu.

Sincerely, Karen R. Petitto, WVU Doctoral Candidate

PO Box 33, West Milford, WV 26451

(304) 473-8378

petitto@wvwc.edu 


\title{
Exhibit B2
}

Procedures to Accompany Instrument One

\author{
Karen R. Petitto \\ Doctoral Candidate \\ Technology Education \\ Department of Advanced Educational Studies \\ West Virginia University \\ Delphi Instrument One
}

Importance Ranking of Metrics Used to Determine the Efficacy of Wireless Communication Systems in Higher Education

\section{PROCEDURE:}

The role of this Delphi panel of experts in the research process is to rank the importance of each metric on a Likert scale of $1-5$, as defined within. The instrument is separated into three sections: (1) Cost, (2) Speed, and (3) Reliability. These rankings will then be used to structure the self-assessment instrument used by a small college administrator as an aid in the decision making process. It should take between 10 and 15 minutes to complete the entire instrument ranking process. 
Exhibit B2, cont.

After completing the ranking process, return this instrument in the return envelope provided. If you have misplaced the envelope, please return to:

Karen R. Petitto

West Virginia University Doctoral Candidate

WVWC Instructional Technology Specialist

59 College Avenue

Buckhannon, WV 26201 


\section{Exhibit B3}

Data Collection Instrument One. Importance Ranking of Metrics Used to Determine the Efficacy of Wireless Communication Systems in Higher Education

\section{Section 1. COST.}

Please read all of the metrics in Section 1 before ranking this section of the instrument. Circle your choice according to this five point Likert scale.

$$
\begin{aligned}
& 1=\text { important to a small extent } \\
& 2=\text { fairly important } \\
& 3=\text { moderately important } \\
& 4=\text { very important } \\
& 5=\text { extremely important }
\end{aligned}
$$

Also, include any modifications you would suggest below each metric. If, from your experience, you find that one or more metric has been omitted, please describe it at the end of this page.

Importance Ranking

1. It is important to be able to calculate the Return

Low

$\begin{array}{lllll}1 & 2 & 3 & 4 & 5\end{array}$
on Investment of a wireless network.

Suggested Modification (if any)

2. It is important to know the total cost of installation of a wireless network.

Suggested Modification (if any)

3. It is important to know the cost of maintenance of a wireless network.

Suggested Modification (if any)

4. It is important to compare the cost of installing wired and wireless systems.

Suggested Modification (if any) 
5. It is important to determine the number of users $\quad \begin{array}{llllll}1 & 2 & 3 & 4 & 5\end{array}$ who will access the wireless network simultaneously.

Suggested Modification (if any)

6. It is important to determine the cost of the training and support for faculty using new teaching $\begin{array}{llllll}1 & 2 & 3 & 4 & 5\end{array}$ and learning resources that the wireless network will make available.

Suggested Modification (if any)

7. It is important to consider the cost of new software the wireless network will make available to faculty and students.

Suggested Modification (if any)

8. It is important to determine the cost of securing the wireless network.

Suggested Modification (if any)

Suggested Additions to Section 1, Cost. (if any)

\section{Section 2. SPEED.}

Please read all of the metrics in Section 2 before ranking this section of the instrument. Circle your choice according to this five point Likert scale.

$$
\begin{aligned}
& 1=\text { important to a small extent } \\
& 2=\text { fairly important } \\
& 3=\text { moderately important } \\
& 4=\text { very important } \\
& 5=\text { extremely important }
\end{aligned}
$$

Also, include any modifications you would suggest below each metric. If, from your experience, you find that one or more metric has been omitted, please describe it at the end of this page. 


\section{Importance Ranking}

Low

1. It is important to calculate the date transfer rate (Mbps) of the servers that support the wireless

1

$\begin{array}{llll}2 & 3 & 4\end{array}$
system.

Suggested Modification (if any)

2. It is important to determine the typical file size that the wireless network will be expected to transport.

Suggested Modification (if any)

3. It is important to determine the number of simultaneous users that the wireless network will support.

Suggested Modification (if any)

4. It is important to determine the available

$\begin{array}{lllll}1 & 2 & 3 & 4 & 5\end{array}$ bandwidth that will support the wireless network.

Suggested Modification (if any)

5. It is important to determine the data transfer rate (Mbps) of the supporting wired infrastructure.

Suggested Modification (if any)

6. It is important for the wired connection to support the same speed rating as the wireless hub to

$\begin{array}{lllll}1 & 2 & 3 & 4 & 5\end{array}$ which it connects.

Suggested Modification (if any)

7. It is important to use the most efficient connection technology that is available to support the wireless network.

Suggested Modification (if any) 
8. It is important to evaluate the data transfer rate (Mbps) of the client computers within the wireless $\begin{array}{lllll}1 & 2 & 3 & 4 & 5\end{array}$ network.

Suggested Modification (if any)

9. It is important to obtain the fastest wireless

$\begin{array}{lllll}1 & 2 & 3 & 4 & 5\end{array}$ network adapters for use in the client computers.

Suggested Modification (if any)

Suggested Additions to Section 2, Speed. (if any)

\section{Section 3. RELIABILITY.}

Please read all of the metrics in Section 3 before ranking this section of the instrument. Circle your choice according to this five point Likert scale.

$$
\begin{aligned}
& 1=\text { important to a small extent } \\
& 2=\text { fairly important } \\
& 3=\text { moderately important } \\
& 4=\text { very important } \\
& 5=\text { extremely important }
\end{aligned}
$$

Also, include any modifications you would suggest below each metric. If, from your experience, you find that one or more metric has been omitted, please describe it at the end of this page.

1. It is important the wireless network be operational 24 hours a day, 7 days a week.

\begin{tabular}{ccccc}
\multicolumn{4}{c}{ Importance Ranking } \\
Low & & & & High \\
1 & 2 & 3 & 4 & 5
\end{tabular}

$$
\text { Suggested Modification (if any) }
$$

2. It is important the wireless network be operational only during times when on-campus courses are in session.

Suggested Modification (if any)

3. Wireless network operational periods vary and are dependent on the teaching and learning activities that are typical in the wireless coverage area.

Suggested Modification (if any) 
4. Range of the wireless hub is an important reliability factor. Suggested Modification (if any)

$\begin{array}{lllll}1 & 2 & 3 & 4 & 5\end{array}$

5. Range of the network adapter is an important reliability factor.

$\begin{array}{lllll}1 & 2 & 3 & 4 & 5\end{array}$

Suggested Modification (if any)

6. The type of building materials in the wireless coverage area is an important factor in network reliability.

Suggested Modification (if any)

7. It is important to determine the response time of support personnel during operational time of the wireless network.

Suggested Modification (if any)

8. It is important the wireless network allow users to simultaneously access the legacy/existing campus system.

Suggested Modification (if any)

9. It is important that the movement of the user from $\begin{array}{lllll}1 & 2 & 3 & 4 & 5\end{array}$ the wired to the wireless network be as easy as possible.

Suggested Modification (if any)

10. It is important the wireless network support the software that faculty and students are most likely to use.

Suggested Modification (if any)

Suggested Additions to Section 3, Reliability 


\title{
APPENDIX C
}

\author{
$\underline{\text { Instrument Two }}$
}

\section{Exhibit C1}

Cover Letter to Accompany Instrument Two

\author{
WVU College of Human Resources and Education Letterhead \\ Dear [Panel Member],
}

Find attached the final instrument in my dissertation research entitled, Identification of Metrics Used to Determine the Efficacy of Wireless Communication Systems in Higher Education; as partial fulfillment for the doctoral degree from the Technology Education Department at West Virginia University. This instrument reflects the panel input from Instrument One; with the categories and ranks aggregated to define self-assessment measures for decision makers in the area of wireless network infrastructure efficacy.

Your continued participation in this research adds to the base of literature on wireless networks in higher education; I value your time and participation in the study. This instrument should take $10-15$ minutes to complete.

As with Instrument One, your responses will remain anonymous and confidential, and you may choose not to respond to any item. Participation in the study is voluntary and final results of the study will be reported to the participants at the conclusion.

Please return Instrument $\mathrm{Two}$ in the self-addressed, stamped envelope that has been provided by Friday, April 11, 2003. An alternative for return is to fax the data sheet and Instrument Two to 304-473-8181. I look forward to receiving your response.

If you have any questions concerning this research, please contact me immediately. My e-mail address is petitto@wvwc.edu; phone (office) 304.473.8378 or (home) 304.745.4783.

Sincerely,

Karen R. Petitto, WVU Doctoral Candidate

59 College Avenue

Buckhannon, WV 26201

(304) 473-8378

petitto@wvwc.edu 


\title{
Exhibit C2
}

Procedures to Accompany Instrument Two

\author{
Karen R. Petitto, Doctoral Candidate
}

Questions decision makers should ask when planning wireless communication systems in small colleges

Reported in the first column of the attached instrument is the consensus ranking of the Level of Importance of each metric included in Round One of this study. The self-assessment measures found in column two of this instrument stem directly from the metrics as they reached consensus in Instrument One. The measures are grouped based on their level of importance ranking. Metrics that reached consensus at 3-5 were sorted into Part 1, Essential Information; metrics that reached consensus at a level below 3 were placed in Part 2, Supplemental Information. The third column contains the area for the panelist response during this round. There is also space provided under each self-assessment measure to note any modification that you recommend.

PROCEDURE:

1. The role of this Delphi panel of experts in the research step is to respond to each self-assessment measure by circling KEEP, DELETE, or MODIFY in column 3 of the instrument.

2. Below each item, if in your expert opinion the item should be modified, please note the modification.

After completing the instrument, return it in the envelope provided. If you have misplaced the envelope, please return to:

Karen R. Petitto

West Virginia University Doctoral Candidate

West Virginia Wesleyan College

59 College Avenue

Buckhannon, WV 26201 


\section{Exhibit C3}

Data Collection Instrument Two. Questions decision makers should ask when planning wireless communications systems in small colleges

\section{Level of Importance Panel Consensus after Round 1}

\section{Self-Assessment Measure}

\begin{abstract}
5 extremely important
\end{abstract}

4.5 very important

4.5 very important

3.5 moderately important

5 extremely important

\section{PART 1. ESSENTIAL INFORMATION}

\section{Section I. Cost}

1. Calculate the number of users who will access the wireless network simultaneously. Note any modification:

2. Calculate the total cost of installation of the wireless network. Note any modification:

3. Calculate the cost of securing the network. Note any modification:

4. Calculate the yearly maintenance cost of the wireless network. Note any modification:

\section{Section II. Speed}

1. Identify the number of simultaneous

\section{Panelist Response}

(circle Keep, Delete, or Modify)

Keep Delete Modify

Keep Delete Modify

Keep Delete Modify

Keep Delete Modify users that the wireless network will support. Keep Delete Modify Note any modification: 
2. Identify the typical file size that the wireless network will be expected to transport.

Note any modification:

3. Identify the available bandwidth (on campus and connection to the Internet) that will support the wireless network.

Note any modification:

4. Identify the data transfer rate (Mbps) of the supporting wired infrastructure.

Note any modification:

5. Compare the speed rating of the wired connection and the wireless hub to which it connects.

Note any modification:

6. Identify the most efficient connection technology that is available to support the wireless network.

Note any modification:

7. Identify the data transfer rate (Mbps) of 3.5 moderately important important the client computers within the wireless network.

Note any modification:
4.5 very

important

4.5 very important

4 very important
Keep Delete Modify

Keep Delete Modify Keep Delete Modify Keep Delete Modify Keep Delete Modify
Keep Delete Modify 


\section{Section III. Reliability}

1. Can you ensure that the wireless network

5 extremely important

5 extremely important

5 extremely important

4.5 very important

4.5 very important

4.5 very important be operational 24 hours a day, 7 days a week?

Note any modification:

2. Identify the range of the wireless hub.

Note any modification:

3. Identify new software that the wireless network will make available to faculty and the new software. (5, extremely important) Note any modification:

4. Identify the type of building materials in the wireless coverage area, and determine if they will affect the wireless signal.

Note any modification:

5. Identify the software that is necessary for the wireless network user to simultaneously access the legacy/existing campus system. Note any modification:

6. Identify the software that is necessary for the wireless network user to move seamlessly from the wired to the wireless network.
Keep Delete Modify students, and calculate the cost of supporting Keep Delete Modify Keep Delete Modify

Keep Delete Modify

Keep Delete Modify Keep Delete Modify

Note any modification: 
7. Determine the response time of support 3.5 moderately important personnel during the operational time of the wireless network.

Keep Delete Modify Note any modification:

Suggested Additions to Part 1, Essential Information. (if any) 


\section{PART 2. SUPPLEMENTAL INFORMATION}

\section{Section I. Cost}

2.5 fairly

important

2.5 fairly

important

2.5 fairly

important

1.5 important to a small extent

2.5 fairly important

2.5 fairly important
1. Compare the cost between the installation of a wired and wireless system.

Keep Delete Modify Note any modification:

2. Calculate the cost associated with training and support for faculty using new teaching and leaning resources that the Keep Delete Modify wireless network will make available. Note any modification:

3. Calculate the cost associated with new software the wireless network will make available to faculty and students.

Keep Delete Modify Note any modification:

4. Calculate the return on investment of the wireless network.

Keep Delete Modify Note any modification:

\section{Section II. Speed}

1. Identify the data transfer rate (Mbps) of the servers that support the wireless system. Note any modification:

2. Identify the speed of the wireless network adapters that you will use in the client computers. Note any modification:
Keep Delete Modify

Keep Delete Modify 


\section{Section III. Reliability}

1. Identify the times when the wireless network capacity will be at its peak (times

1.5 important to a small extent

2.5 fairly important network, or other high use times).

Note any modification:

2. Identify the optimum speed for the the client computer.
B13when classes will be using the wireless

Keep Delete Modify wireless network adapter that will be used in Keep Delete Modify

Note any modification:

Suggested Additions to Part 2, Supplemental Information. (if any) 


\section{Exhibit C4}

$\underline{\text { Consensus Detail for Self-Assessment Questions for Decision Makers }}$

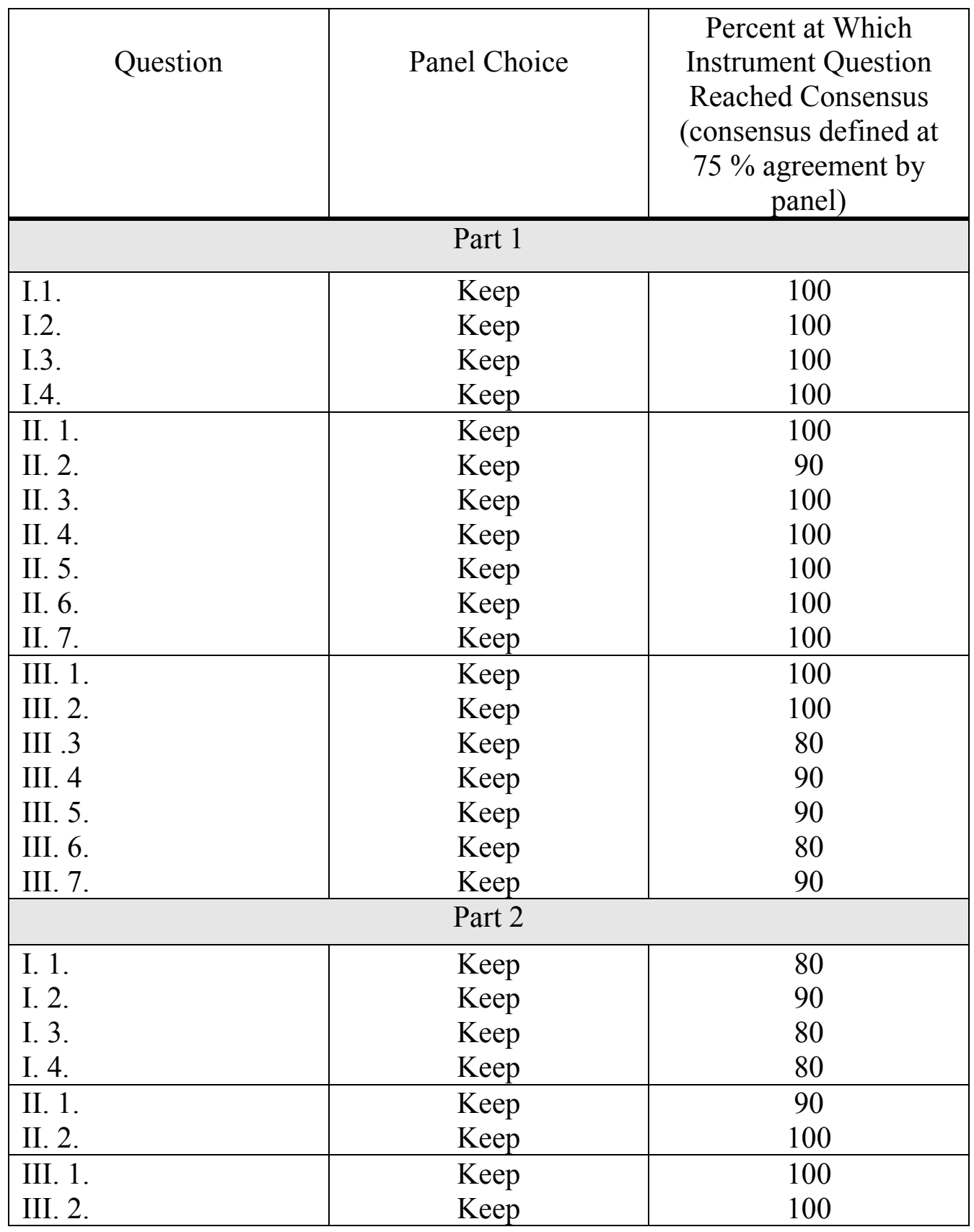




\title{
APPENDIX D
}

\section{Self-Assessment Instrument}

\author{
Exhibit D1
}

\section{Suggested Modifications by Expert Panel to Self-Assessment Questions}

\begin{tabular}{|c|c|}
\hline $\begin{array}{l}\text { Self-Assessment } \\
\text { Question }\end{array}$ & Suggested Modifications \\
\hline $\begin{array}{l}\text { I.3. Calculate the cost of } \\
\text { securing the network. }\end{array}$ & $\begin{array}{l}\text { 1. Should be included in security of wired network and } \\
\text { cost no more. } \\
\text { 2. In Higher Ed } 8 \text { of } 10 \text { are being left open. }\end{array}$ \\
\hline $\begin{array}{l}\text { II.1. Identify the number of } \\
\text { simultaneous users that the } \\
\text { wireless network will } \\
\text { support. }\end{array}$ & $\begin{array}{l}\text { 1. The potential number, would be more specific and } \\
\text { realistic }\end{array}$ \\
\hline $\begin{array}{l}\text { II. } 5 . \text { Compare the speed } \\
\text { rating of the wired } \\
\text { connection and the wireless } \\
\text { hub to which it connects. }\end{array}$ & $\begin{array}{l}\text { 1. Re-word, without using the word "hub.' Our wired } \\
\text { connections are from wired switches to "access points" } \\
\text { with both a wired connection and a radio- } \\
\text { transmitter/card. } \\
\text { 2. This level of importance can downgrade - it could be } \\
\text { viewed as a variable due to simply replacing/upgrading a } \\
\text { component }\end{array}$ \\
\hline $\begin{array}{l}\text { III. 1. Can you ensure that } \\
\text { the wireless network be } \\
\text { operational } 24 \text { hours a day, } 7 \\
\text { days a week? }\end{array}$ & 1. Reword, asking for typical up-time statistics. \\
\hline $\begin{array}{l}\text { III. 2. Identify the range of } \\
\text { the wireless hub. }\end{array}$ & $\begin{array}{l}\text { 1. Identify the range of each type of wireless } \\
\text { transmitter/antenna. }\end{array}$ \\
\hline $\begin{array}{l}\text { III. 4. Identify the type of } \\
\text { building materials in the } \\
\text { wireless coverage area, and } \\
\text { determine if they will affect } \\
\text { the wireless signal. }\end{array}$ & 1. Also potential interference - i.e. cordless telephones \\
\hline $\begin{array}{l}\text { III } 5 \text {. Identify the software } \\
\text { that is necessary for the } \\
\text { wireless network user to } \\
\text { move seamlessly from the } \\
\text { wired to the wireless } \\
\text { network. }\end{array}$ & $\begin{array}{l}\text { 1. This should be built into the OS. } \\
\text { 2. "Identify the hardware and software..." }\end{array}$ \\
\hline
\end{tabular}




\title{
Exhibit D2
}

Self-Assessment Instrument

\section{A Self-Assessment Instrument: Questions Decision Makers Should Ask When Planning Wireless Communication Systems in Small Colleges}

\author{
Author: Karen R. Petitto
}

This self-assessment instrument was designed as a tool for professionals who are responsible for developing a wireless local area network on small college campuses to facilitate faculty and student wireless communication channels.

\section{How was this self-assessment instrument developed?}

Extensive research was conducted to generate this self-assessment instrument. The assessment tools it contains were taken from published materials and verified by a modified Delphi study with professionals nationwide who were identified as experts in the field of wireless local area networks in higher education. Each expert was employed by a small college with established wireless local area networks, or worked in the wireless industry and had a minimum of two years of experience in development and deployment of wireless LANs in higher education. Experts also held a minimum of a Bachelor's Degree and had presented or published either regionally or nationally.

\section{What are the components of this self-assessment instrument?}

The instrument is divided into two sections. The first section asks the wireless decision makers to collect essential information that will be necessary to make decisions when planning a wireless local area network on a small college campus. The second section is optional in wireless system planning, providing the decision maker with more in-depth study of the implementation strategies that are specific to the individual campus.

\section{What is the benefit of completing this self-assessment instrument?}

By collecting the information in the essential area of the instrument you will be able to analyze all the components of efficacy of a wireless system and therefore; make an informed decision on the procurement and deployment of a wireless system at a specific institution of higher education. Decision-makers who choose to collect the information located in the supplemental information section of the instrument will also be able to apply cost/benefit analysis to the wireless system and have a more in-depth plan for implementation of the wireless system into the teaching and learning process.

DRAFT 6-24-03 by Karen R. Petitto 


\section{Section One \\ Essential Information}

Section one focuses on the information that it is essential to collect in order to make good decisions about the wireless system that will best compliment your existing infrastructure. The three categories in which you will be collecting information are cost, speed, and reliability. Record the information that correlates to each question in Section one. This information can then be used to determine the specifications that your wireless system installation must meet.

\section{PART ONE. RELIABILITY}

1. Can you ensure that the wireless network be operational 24 hours a day, 7 days a week?

2. Identify the range of each wireless access points and network adapters (all wireless transmitter/antennas) within the proposed system.

3. Identify new hardware and software that the wireless network will make available to faculty and students, and calculate the cost of supporting the new software. 
4. Identify the type of building materials in the wireless coverage area, and determine if they will affect the wireless signal. Also identify devices that may cause potential interference.

5. Identify the software that is necessary for the wireless network user to simultaneously access the legacy/existing campus system.

6. Identify the hardware and software that is necessary for the wireless network user to move seamlessly from the wired to the wireless network.

7. Determine the response time of support personnel during the operational time of the wireless network. 


\section{PART TWO. SPEED}

1. Identify the potential number of simultaneous users that the wireless network will support.

2. Identify the typical file size that the wireless network will be expected to transport.

3. Identify the available bandwidth (on campus and connection to the Internet) that will support the wireless network.

4. Identify the data transfer rate (Mbps) of the supporting wired infrastructure.

5. Compare the speed rating of the wired connection and the wireless access point to which it connects. 
6. Identify the most efficient connection technology that is available to support the wireless network.

7. Identify the data transfer rate (Mbps) of the client computers within the wireless network.

\section{PART THREE. COST}

1. Calculate the number of users who will access the wireless network simultaneously.

2. Calculate the total cost of installation of the wireless network. 
3. Calculate the cost of securing the network.

4. Calculate the yearly maintenance cost of the wireless network.

5. Calculate any savings the wireless network will produce as a function of networked hardware and software resources (shared software, printers, Ethernet connections, etc...) 


\section{Section Two \\ $\underline{\text { Supplemental Information }}$}

Collection of this supplemental information is optional for the wireless system decision maker. The supplemental information may be beneficial in creating an investment or use analysis of the wireless system.

1. Identify the times when the wireless network capacity will be at its peak (times when classes will be using the wireless network, or other high use times.)

2. Identify the data transfer rate (Mbps) of the servers that support the wireless system.

3. Identify the speed of the wireless network adapters that you will use in the client computers.

4. Compare the cost between the installation of a wired and wireless system.

5. Calculate the cost associated with training and support for faculty using new teaching and leaning resources that the wireless network will make available.

6. Calculate the cost associated with new software the wireless network will make available to faculty and students.

7. Calculate the return on investment of the wireless network. 


\section{VITA}

\section{KAREN R. PETITTO}

P. O. Box 33

West Milford, WV 26451

Voice: (o) 304.473.8378 (h) 304.745.4783

E-mail: petitto@wvwc.edu

\section{EDUCATION}

West Virginia University. (2003). Doctor of Education in Technology Education. Major: Technology and Society. Minors: Computer Information Systems and Educational Technology.Anticipated completion of degree requirements, May, 2002. Emphases: Communication, Technology in Society, and Educational Technology

University of North Carolina Greensboro. (1989). Master of Education. Textiles and Clothing. Emphases: Merchandising, Research, and Business Operations

Fairmont State College. (1985). Bachelor of Arts. Major: Home Economics Education. Minor: Retail Management.

\section{EXPERIENCE}

\section{West Virginia Wesleyan College}

Instructional Technology Specialist

Assistant Professor of Educational Technology

May, 1997 - Present

Assistant Professor of Family and Consumer Sciences

$1992-1997$

\section{Academic Computing Responsibilities}

- Faculty Technology Mentor

- Campus-wide mobile computer implementation

- College-wide curriculum development and technology integration

- Development of Campus-wide annual Faculty Technology Workshop

- Computer Literacy Program Coordinator 
- ThinkPad Training Coordinator

- Interdisciplinary Course Development

- Software Evaluation and Recommendation

- Grant Writing

- Web Page Development

\section{Committee and Other Responsibilities}

- WVWC Council on Technology

- WVWC Teaching, Learning, and Technology Roundtable, Chair

- Technology Representative to Appalachian College Association (ACA)

- Steering Committee for ACA Technology Summit

- West Virginia High Tech Consortium Higher Education Advisory Council

- Subcommittee on Contract Learning

- Service-Learning Committee

- Leadership Task Force

- Peer Evaluation Committees

\section{Academic Instruction}

- Computers and Technology in Education

- Computer Literacy

- Audio-Visual Methods in Education

- Computer Science Internship

- Science \& Technology Core - an Interdisciplinary Course in Physics, Algebra, and Computer Literacy

- Professional Development Seminar

- Retailing and Merchandising Curriculum

\section{Publications}

Maughan, G., Petitto, K. R., \& McLaughlin, D. (2001). Networks. Technology leadership: Communication and information systems in higher education. Maughan, G., (Ed.) San Francisco: Jossey-Bass.

Brown, D. G., Petitto, K. R. (2003). The status of ubiquitous csomputing. Educause Review, (38) 3, 24-33. 


\section{Grant Funding}

- Mellon Technology Grant - 1998-2000, Student Technology Assistant Training Grant

- T.I.I.A.P./Department of Commerce Grant - 1997-1999, taking mobile computing into the rural community

- Eisenhower Grant - 1998, Technology Consultant, Project Watershed, K-12 Science Teachers and WV Watersheds.

- National Science Foundation, EPSCor/WVFIC - 1997-98, interdisciplinary course development in Physics, Algebra, and Computer Literacy

- WVWC Faculty Innovation Grant - 1995, historical research grant

- WVWC Service Innovation Grant - 1994, integrating service in the undergraduate classroom

- WVWC/PEW Grant - 1995, incorporating communication skills into the undergraduate classroom

\section{Research and Workshop Presentations}

- IBM ThinkPad University Seminars - Campus Networking, Ubiquitous Computing and Faculty Initiatives, Microsoft Office: Use in the Networked Classroom Environment, Computer Integration in Higher Education

- Higher Education Technology Consultant - Southwestern College, Winfield, KS, Emory \& Henry College, Emory, VA

- Upward Bound TRIO Programs - design and implementation of computer education for college-bound high school juniors and seniors

- WV Family and Consumer Sciences Association, 1995. ADA: Technological Implications in Education

- WV Family and Consumer Sciences Association, 1996. Innovative Teaching Strategies in Higher Education: Service-Learning

- Upshur County Schools, 1994, Public Relation Skills for Secondary School Personnel

- Technology Summit, Appalachian College Association, 1998. Network Computing in Higher Education

- Technology Summit, Appalachian College Association, 1999. Workshop: Tutorials and Interactive Uses of Microsoft Office Applications

- Technology Summit, Appalachian College Association, 1998. Workshop: Classroom Management: Leave it to the software, you're job is to facilitate learning!

- National Bonner Summit, 1996. Presentation on Presentations 
- West Virginia Foundation of Independent Colleges, 1999. Interdisciplinary course development and facilitation in Physics, Mathematics and Computer Science

- Eastern Communication Association, 1999. Technology in Higher Education Panel: Computer Mediated Communication in Higher Education

- EduCause/Council of Independent Colleges National Technology Workshop, 1999. Mobile Computing: Enhancing the Liberal Arts Experience

- EduCause/Council of Independent Colleges National Technology Workshop, 2000. Transforming a Distance Education Degree Program: RN/BSN Completion

- IBM Santa, 1998. Implementing ThinkPads in the Liberal Arts College

- Appalachian College Association, TLTR, 1999. Student Technology Assistants and the Success of a College-wide Technology Plan.

- Appalachian College Association, TLTR, 1999. Science and Technology Core, Interdisciplinary Classroom Success

- National Computers on Campus Conference, sponsored by the University of South Carolina, 1998. Network Computing in Higher Education

- West Virginia EPSCOR, 1998. Development of a Studio Course in Science and Technology

- West Virginia University Technology Fair, 1999. Mobile Computing: Enhancing the Liberal Arts Experience

- Student Technology Assistant Collaborative Venture, 1999. Technology Customer Service: Emphasis on Customer Service

\section{Workshop/Seminar Participation}

- AAC\&U National Conference

- AAHE National and Regional events

- National Science Foundation's Project kaleidoscope-Initiatives in Undergraduate Mathematics

- International Conference on College Teaching and Learning

- Regional Teaching, Learning, and Technology Roundtable Events

- C-CUE Regional Events

- Bonner Campus Services programs Summit

- Writing/Communication/Critical Thinking across the Curriculum

- Primary Trait Assessment Workshop

- Technology in Education Workshop

- University of Virginia's Jepson School Leadership Conference 